\title{
Supplementary Table S5
}

Extensive overview of significant expression changes in 16-week old wild-type mice compared to 8-week-old mice, FC: fold change, p: p-value.

\section{Code}

1449526_a_at

1435135_at

1418148_at

1446205_at

1435188_at

1455282_x_at

1442364_at

1417169_at

1425019 at

1421056_at

1460662_at

1417714_x_at

1438211_s_at

1455886_at

1452677_at

1456590_x_at

1417462_at

1426366_at

1420947_at

1429466_s_at

1443923_at

1449876_at

1457877_at

1445042_at

1440651 at

1437082_at

1458832_at

1418989_at

1446284_at

1436746_at

\section{Title}

glycerophosphodiester phosphodiesterase domain containing 3

arylacetamide deacetylase-like 1

abhydrolase domain containing 1

Nuclear transcription factor-Y gamma

similar to hypothetical protein BC017397

aminolevulinic acid synthase 1

Mitogen activated protein kinase 14

ubiquitin specific protease 2

UBX domain containing 4

deoxyribonuclease 1-like 3

period homolog 3 (Drosophila)

hemoglobin alpha, adult chain 1

D site albumin promoter binding protein

Casitas B-lineage lymphoma

polyribonucleotide nucleotidyltransferase 1

aldo-keto reductase family 1 , member B3 (aldose reductase)

$\mathrm{CAP}$, adenylate cyclase-associated protein 1 (yeast)

eukaryotic translation initiation factor $2 \mathrm{C}, 2$

alpha thalassemia/mental retardation syndrome X-linked homolog (human)

anterior pharynx defective $1 \mathrm{c}$ homolog (C. elegans)

A kinase (PRKA) anchor protein 13

protein kinase, cGMP-dependent, type I

Estrogen receptor 1 (alpha)

Aminoadipate-semialdehyde synthase

Dual specificity phosphatase 16

A kinase (PRKA) anchor protein (yotiao) 9

Growth hormone receptor

\section{cathepsin E}

Metastasis suppressor 1

protein kinase, lysine deficient 1

\section{Symbol}

Gdpd3

Aadacl1

Abhd1

Nfyc

LOC433627

Alas1

Mapk14

Usp2

Ubxd4

Dnase1/3

Per3

Hba-a1

Dbp

Cbl

Pnpt1

Akr1b3

Cap1

Eif2c2

Atrx

Aph1c

Akap13

Prkg1

Esr1

Aass

Dusp16

Akap9

Ghr

Ctse

Mtss1

Prkwnk1
$16 \mathrm{~W}$

FC

$58.79 \quad 0.000$

$24.76 \quad 0.001$

$8.67 \quad 0.000$

$\begin{array}{ll}8.27 & 0.001\end{array}$

0.000

0.000

0.001

0.000

0.000

0.001

0.001

0.001

0.000

0.000

0.005

0.000

0.006

0.004

0.002

0.000

0.000

0.000

0.002

0.000

0.000

0.000

0.000

0.002

0.002

0.003 
1420342_at

1421704 a at

1430309_at

1452816_at

1442058_s_at

1448975_s_at

1453913_a_a

1447761_x_a

1449311

1452456_at

1458699 at

1443675_at

1440972_at

1437221_at

1419717_at

1453189_at

1423249_at

1455057_at

1444166_at

1449365_at

1457123_at

1448523_at

1437884_at

1438439 at

1424504_at

1439109_at

1425239 at

1425795_a_at

1423152_at

1442682_at

1446904_at

1425687_at

1450109_s_at

1456764 at

1435287_at

1416490_at
Ganglioside-induced differentiation-associated-protein 10

phosphatidylinositol 3-kinase, C2 domain containing, gamma polypeptide

Nipped-B homolog (Drosophila)

myeloid leukemia factor 1 interacting protein

proteasome (prosome, macropain) 26S subunit, ATPase 3 , interacting protein

renin 1 structural /// renin 2 tandem duplication of Ren1

transporter 2, ATP-binding cassette, sub-family B (MDR/TAP)

superoxide dismutase 1 , soluble

BTB and CNC homology 1

nuclear receptor interacting protein 2

R4 carbon catabolite repression 4-like (S. cerevisiae)

Enhancer of polycomb homolog 1 (Drosophila)

nuclear receptor-binding SET-domain protein 1

ribonucleotide reductase M2 B (TP53 inducible)

semaphorin 3E

ubiquitin-conjugating enzyme E2

natural killer tumor recognition sequence

Guanine monphosphate synthetase

thyroid hormone responsive SPOT14 homolog (Rattus)

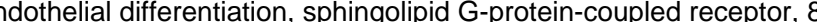

neuregulin 4

nephronophthisis 1 (juvenile) homolog (human)

ADP-ribosylation factor-like 8

G protein-coupled receptor 171

RAB22A, member RAS oncogene family

similar to CTCL tumor antigen se57-1

open reading frame 21

mitogen activated protein kinase kinase kinase 7

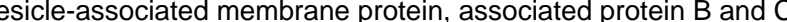

Wee 1 homolog (S. pombe)

Rho guanine nucleotide exchange factor (GEF) 11

CASP8 and FADD-like apoptosis regulator

ATP-binding cassette, sub-family C (CFTR/MRP), member 2

solute carrier family 35 , member $\mathrm{F} 3$

adducin 2 (beta)

transmembrane emp24 protein transport domain containing 6

\begin{tabular}{lll} 
Gdap10 & 4.34 & 0.000 \\
Pik3c2g & 4.33 & 0.000 \\
Nipbl & 4.31 & 0.000 \\
Mlf1ip & 4.30 & 0.008 \\
Psmc3ip & 4.21 & 0.002 \\
Ren1 III Ren2 & 4.20 & 0.002 \\
Tap2 & 3.92 & 0.000 \\
Sod1 & 3.91 & 0.008 \\
Bach1 & 3.70 & 0.007 \\
Nrip2 & 3.65 & 0.010 \\
Ccrn4l & 3.64 & 0.006 \\
Epc1 & 3.61 & 0.009 \\
Nsd1 & 3.61 & 0.000 \\
Rrm2b & 3.61 & 0.003 \\
Sema3e & 3.58 & 0.000 \\
Ube2i & 3.58 & 0.002 \\
Nktr & 3.57 & 0.008 \\
Gmps & 3.50 & 0.001 \\
Thrsp & 3.50 & 0.001 \\
Edg8 & 3.49 & 0.000 \\
Nrg4 & 3.48 & 0.001 \\
Nphp1 & 3.45 & 0.006 \\
Arl8 & 3.44 & 0.000 \\
Gpr171 & 3.42 & 0.006 \\
Rab22a & 3.39 & 0.010 \\
MGC54896 & 3.38 & 0.007 \\
ORF21 & 3.38 & 0.001 \\
Map3k7 & 3.36 & 0.000 \\
Vapb & 3.34 & 0.000 \\
Wee1 & 3.34 & 0.004 \\
Arhgef11 & 3.34 & 0.002 \\
Cflar & 3.31 & 0.000 \\
Abcc2 & 3.30 & 0.008 \\
Slc35f3 & 3.30 & 0.002 \\
Add2 & 3.30 & 0.002 \\
Tmed6 & 3.29 & 0.004 \\
\hline & & \\
\hline
\end{tabular}




\begin{tabular}{|c|c|c|c|c|}
\hline 1425617_at & DEAH (Asp-Glu-Ala-His) box polypeptide 9 & Dhx9 & 3.29 & 0.001 \\
\hline 1434020 at & PDGFA associated protein 1 & Pdap1 & 3.29 & 0.007 \\
\hline 1423138_at & WD repeat domain 4 & Wdr4 & 3.28 & 0.000 \\
\hline 1430700_a_at & phospholipase A2, group VII & Pla2g7 & 3.26 & 0.009 \\
\hline 1460059_at & uridine phosphorylase 2 & Upp2 & 3.25 & 0.000 \\
\hline 1422230_s_at & cytochrome $\mathrm{P} 450$, family 2 , subfamily a, polypeptide 4 & Сур2а4 & 3.24 & 0.001 \\
\hline 1446966_at & Hypothetical protein E230025K15 & E230025K15 & 3.23 & 0.006 \\
\hline 1451807_at & nuclear receptor subfamily 1 , group I, member 2 & $\mathrm{Nr} 1 \mathrm{i} 2$ & 3.22 & 0.009 \\
\hline 1441008_at & dymeclin & Dym & 3.22 & 0.000 \\
\hline 1454655_at & diacylglycerol kinase, delta & Dgkd & 3.22 & 0.004 \\
\hline 1454200 at & zinc finger homeobox $1 b$ & $Z$ fhx $1 b$ & 3.19 & 0.002 \\
\hline 1418480_at & chemokine (C-X-C motif) ligand 7 & $\mathrm{Cxcl} 7$ & 3.18 & 0.001 \\
\hline 1454158_at & membrane protein, palmitoylated 7 (MAGUK p55 subfamily member 7 ) & Mpp7 & 3.17 & 0.002 \\
\hline 1425638_at & centaurin, alpha 2 & Centa2 & 3.17 & 0.004 \\
\hline 1422894_at & Scm-like with four mbt domains 1 & Sfmbt1 & 3.16 & 0.001 \\
\hline 1452344_at & synaptojanin 2 & Synj2 & 3.16 & 0.006 \\
\hline 1456316_a_at & acyl-Coenzyme A binding domain containing 3 & Acbd3 & 3.15 & 0.010 \\
\hline 1443083_at & Cleavage and polyadenylation specific factor 2 & Cpsf2 & 3.14 & 0.004 \\
\hline 1429489_at & transcription elongation factor B polypeptide 3 binding protein 1 & Tceb3bp1 & 3.13 & 0.008 \\
\hline 1446807_at & Ubiquitin specific protease 8 & Usp8 & 3.12 & 0.000 \\
\hline 1438771_at & bromodomain containing 1 & Brd1 & 3.09 & 0.001 \\
\hline 1436544 at & ATPase, Class V, type 10D & Atp10d & 3.05 & 0.002 \\
\hline 1444931_at & Endothelial-specific receptor tyrosine kinase & Tek & 3.04 & 0.004 \\
\hline 1416065_a_at & ankyrin repeat domain 10 & Ankrd10 & 3.01 & 0.004 \\
\hline 1423530_at & serine/threonine kinase $32 \mathrm{C}$ & Stk32c & 3.01 & 0.000 \\
\hline 1438246_at & casein kinase 1, gamma 1 & Csnk1g1 & 3.00 & 0.005 \\
\hline 1417904_at & DNA cross-link repair 1A, PSO2 homolog (S. cerevisiae) & Dclre1a & 2.99 & 0.000 \\
\hline 1433780_at & ubinuclein 1 & Ubn1 & 2.99 & 0.006 \\
\hline 1424167_a_at & phosphomannomutase 1 & Pmm1 & 2.99 & 0.000 \\
\hline 1423971_at & THO complex 3 & Thoc3 & 2.98 & 0.005 \\
\hline 1431182_at & heat shock protein 8 & Hspa8 & 2.98 & 0.001 \\
\hline 1423867_at & serine (or cysteine) proteinase inhibitor, clade A, member $3 \mathrm{~K}$ & Serpina3k & 2.97 & 0.003 \\
\hline 1451293_at & RNA, U3 small nucleolar interacting protein 2 & Rnu3ip2 & 2.97 & 0.002 \\
\hline 1456653_a_at & methylenetetrahydrofolate dehydrogenase (NADP+ dependent) 1-like & Mthfd1l & 2.96 & 0.004 \\
\hline 1418057_at & T-cell lymphoma invasion and metastasis 1 & Tiam1 & 2.95 & 0.001 \\
\hline 1439972_at & ethanolamine kinase 1 & Etnk1 & 2.94 & 0.001 \\
\hline
\end{tabular}


1416737_at

1439197_at

1437106_at

1452431_s_at

1417705_at

1439760_x_at

1450188_s_at

1460212_at

1424367_a_a

1429656_at

1448506_at

1417297_at

1426758_s_at

1426259_at

1452708_a_at

1433617_s_at

1456656_at

1442186 at

1427379_at

1430781 at

1448147_at

1422415_at

1441291_at

1456499 at

1428951_at

1451731_at

1438009 at

1417709_at

1436123_at

1420832_at

1449292_at

1451983_at

1425477_x_at

1430384_at

1429267_at

1421099_at glycogen synthase 3, brain

phosphatidylinositol 4-kinase, catalytic, beta polypeptide

jumonji, AT rich interactive domain 1A (Rbp2 like)

histocompatibility 2, class II antigen A, alpha

OTU domain, ubiquitin aldehyde binding 1

oplakin 1B

lipase, endothelial

guanine nucleotide binding protein, alpha transducing 1

homer homolog 2 (Drosophila)

Rho-related BTB domain containing 1

serine (or cysteine) proteinase inhibitor, clade A, member 6

inositol 1,4,5-triphosphate receptor 3

, imprinted maternally expressed untranslated mRNA

pantothenate kinase 3

Luc7 homolog (S. cerevisiae)-like

UDP-Gal:betaGIcNAc beta 1,4-galactosyltransferase, polypeptide 5

lin 7 homolog a (C. elegans)

spinocerebellar ataxia 7 homolog (human)

Neuropathy target esterase

adenylate kinase 7

tumor necrosis factor receptor superfamily, member 19

angiogenin, ribonuclease A family, member 2

$\mathrm{v}$-abl Abelson murine leukemia oncogene 1

Ring finger protein 130

nucleolar protein 8

ATP-binding cassette, sub-family A (ABC1), member 3

histone 1, H2ad

cytochrome P450, family 46, subfamily a, polypeptide 1

bassoon

quiescin Q6

RB1-inducible coiled-coil 1

Iroquois related homeobox 1 (Drosophila)

histocompatibility 2, class II antigen A, beta

transducin-like enhancer of split 4, homolog of Drosophila $E(\mathrm{spl})$

thioesterase, adipose associated

basic helix-loop-helix domain containing, class B3

\begin{tabular}{lll} 
Gys3 & 2.93 & 0.005 \\
Pik4cb & 2.93 & 0.010 \\
Jarid1a & 2.90 & 0.005 \\
H2-Aa & 2.88 & 0.007 \\
Otub1 & 2.86 & 0.001 \\
Upk1b & 2.80 & 0.008 \\
Lipg & 2.80 & 0.003 \\
Gnat1 & 2.79 & 0.002 \\
Homer2 & 2.79 & 0.000 \\
Rhobtb1 & 2.78 & 0.003 \\
Serpina6 & 2.78 & 0.006 \\
Itpr3 & 2.78 & 0.005 \\
Gtl2 & 2.77 & 0.003 \\
Pank3 & 2.76 & 0.010 \\
Luc71 & 2.76 & 0.006 \\
B4galt5 & 2.76 & 0.002 \\
Lin7a & 2.75 & 0.005 \\
Sca7 & 2.75 & 0.005 \\
Nte & 2.75 & 0.005 \\
Ak7 & 2.74 & 0.008 \\
Tnfrsf19 & 2.73 & 0.001 \\
Ang2 & 2.73 & 0.005 \\
Abl1 & 2.72 & 0.004 \\
Rnf130 & 2.71 & 0.003 \\
Nol8 & 2.70 & 0.003 \\
Abca3 & 2.69 & 0.000 \\
Hist1h2ad & 2.69 & 0.001 \\
Cyp46a1 & 2.69 & 0.000 \\
Bsn & 2.68 & 0.004 \\
Qscn6 & 2.68 & 0.000 \\
Rb1cc1 & 2.68 & 0.005 \\
Irx1 & 2.68 & 0.001 \\
H2-Ab1 III Rmcs1 & 2.68 & 0.005 \\
Tle4 & 2.67 & 0.003 \\
Thea & 2.67 & 0.000 \\
Bhlhb3 & 2.66 & 0.004 \\
\hline & & \\
\hline
\end{tabular}


1451989_a_at

1434499_a_at

1417623_at

1457306_at

1447791_s_at

1443003_at

1426850_a_at

1416933_at

1448978 at

1451593_at

1453851_a_at

1419266_at

1431316_at

1440966_at

1441988_at

1418495_at

1449042_at

1416334 at

1444430_at

1425317_x_at

1460651_at

1418431_at

1442092_at

1437658_a_a

1422142_at

1457027_at

1446824 at

1458891_at

1416988_at

1419391_at

1449306_at

1427995_at

1417890_at

1456623_at

1425284_a_at

1425139_at microtubule-associated protein, RP/EB family, member 2

lactate dehydrogenase 2 , B chain

solute carrier family 12 , member 2

Polymerase (DNA directed), epsilon 3 (p17 subunit)

guanine nucleotide binding protein, alpha 14

Atpase, class VI, type 11C

mitogen activated protein kinase kinase 6

P450 (cytochrome) oxidoreductase

neuronal guanine nucleotide exchange facto

Histocompatibility 2, D region locus 1

growth arrest and DNA-damage-inducible 45 gamma

nuclear transcription factor-Y beta

Membrane-associated ring finger ( $\mathrm{C} 3 \mathrm{HC} 4) 7$

protein phosphatase $1 \mathrm{~K}$ (PP2C domain containing)

zinc finger $\mathrm{CCCH}$ type domain containing 8

CCCTC-binding factor

WW domain-containing oxidoreductase

Armadillo repeat containing 8

serine threonine kinase 31

linker for activation of $\mathrm{T}$ cells

kinesin family member $5 \mathrm{~B}$

Fanconi anemia, complementation group D2

RNA, U22 small nucleolar

nephrosis 1 homolog, nephrin (human)

dehydrogenase E1 and transketolase domain containing 1

Phosphoglucomutase 1

GTPase activating RANGAP domain-like 3

momolog 2 (E. coli)

myogenin

heat shock factor 2

carboxypeptidase A5

pyridoxal (pyridoxine, vitamin B6) phosphatase

tropomyosin 1, alpha

RAB27A, member RAS oncogene family

sestrin 2

\begin{tabular}{lll} 
Mapre2 & 2.65 & 0.001 \\
Ldh2 & 2.65 & 0.008 \\
Slc12a2 & 2.65 & 0.004 \\
Pole3 & 2.65 & 0.007 \\
Gna14 & 2.64 & 0.003 \\
Atp11c & 2.63 & 0.004 \\
Map2k6 & 2.63 & 0.000 \\
Por & 2.61 & 0.009 \\
Ngef & 2.61 & 0.002 \\
H2-Q1 & 2.61 & 0.007 \\
Gadd45g & 2.59 & 0.004 \\
Nfyb & 2.56 & 0.005 \\
Itch & 2.54 & 0.002 \\
Axot & 2.54 & 0.007 \\
Ppm1k & 2.53 & 0.005 \\
Zc3hdc8 & 2.52 & 0.001 \\
Ctcf & 2.52 & 0.006 \\
Wwox & 2.52 & 0.000 \\
Armc8 & 2.52 & 0.000 \\
Stk31 & 2.52 & 0.002 \\
Lat & 2.51 & 0.001 \\
Kif5b & 2.50 & 0.000 \\
Fancd2 & 2.48 & 0.010 \\
Rnu22 & 2.47 & 0.005 \\
Nphs1 & 2.47 & 0.004 \\
Dhtkd1 & 2.47 & 0.000 \\
Pgm1 & 2.47 & 0.002 \\
Garnl3 & 2.46 & 0.009 \\
Msh2 & 2.46 & 0.003 \\
Myog & 2.45 & 0.004 \\
Hsf2 & 2.44 & 0.004 \\
Cpa5 & 2.43 & 0.002 \\
Pdxp & 2.42 & 0.003 \\
Tpm1 & 2.42 & 0.009 \\
Rab27a & 2.42 & 0.000 \\
Sesn2 & 2.41 & 0.006 \\
\hline
\end{tabular}


1448759_at

1428294_at

1440771_at

1456941_at

1450387_s_at

1434178 at

1417385_at

1453864_at

1457350_at

1418221_at

1433570_s_at

1442511_at

1440193_at

1456058_at

1429911_at

1417513_at

1455108_at

1425824_a_at

1451260_at

1434643 at

1421061_at

1426704_at

1421229_at

1420865 at

1425365_a_at

1430519_a_at

1429057 at

1428449_at

1456416_at

1457357_at

1427813_at

1455509_at

1445824_at

1455204 at

1439381_x_at

1426327_s_at interleukin 2 receptor, beta chain

zinc finger protein 259

zinc finger with KRAB and SCAN domains 1

telomerase reverse transcriptase

adenylate kinase 3 alpha-like 1

myeloid/lymphoid or mixed-lineage leukemia 3

aminopeptidase puromycin sensitive

retinol dehydrogenase 14 (all-trans and 9-cis)

period homolog 2 (Drosophila)

casein delta

MAK10 homolog, amino-acid $\mathrm{N}$-acetyltransferase subunit, (S. cerevisiae)

Importin 7

Ankyrin repeat domain 12

RNA binding motif protein 27

microcephaly, primary autosomal recessive 1

ecotropic viral integration site 5

eukaryotic translation initiation factor 4E member 2

proprotein convertase subtilisin/kexin type 4

aldehyde dehydrogenase 1 family, member B1

(beta)-like 1 X-linked

guanylate cyclase activator $1 a$ (retina)

cyclin $\mathrm{G}$ associated kinase

DNA fragmentation factor, beta subunit

zinc finger protein 161

cytochrome P450, family 2 , subfamily $d$, polypeptide 13

CCR4-NOT transcription complex, subunit 7

NMDA receptor regulated 1-like

general transcription factor IIIC, polypeptide 2, beta

core-binding factor, runt domain, alpha subunit 2

Tousled-like kinase 2 (Arabidopsis)

iduronate 2-sulfatase

similar to mKIAA0363 protein

zinc finger protein 458

phosphatidylinositol transfer protein, cytoplasmic 1

MARVEL (membrane-associating) domain containing 1

ciliary neurotrophic factor /// zinc finger protein 91

\begin{tabular}{lll} 
II2rb & 2.40 & 0.003 \\
Zfp259 & 2.40 & 0.001 \\
Zkscan1 & 2.40 & 0.006 \\
Tert & 2.40 & 0.002 \\
Ak3l1 & 2.39 & 0.000 \\
MIl3 & 2.39 & 0.000 \\
Npepps & 2.39 & 0.000 \\
Rdh14 & 2.38 & 0.000 \\
Per2 & 2.38 & 0.008 \\
Csnd & 2.38 & 0.007 \\
Mak10 & 2.38 & 0.001 \\
Ipo7 & 2.37 & 0.001 \\
Ankrd12 & 2.36 & 0.005 \\
Rbm27 & 2.36 & 0.003 \\
Mcph1 & 2.35 & 0.000 \\
Evi5 & 2.35 & 0.002 \\
Eif4e2 & 2.35 & 0.005 \\
Pcsk4 & 2.35 & 0.000 \\
Aldh1b1 & 2.35 & 0.009 \\
Tbl1x & 2.34 & 0.006 \\
Guca1a & 2.34 & 0.000 \\
Gak & 2.33 & 0.003 \\
Dffb & 2.33 & 0.008 \\
Zfp161 & 2.33 & 0.001 \\
Cyp2d13 & 2.33 & 0.003 \\
Cnot7 & 2.33 & 0.000 \\
Narg1l & 2.33 & 0.000 \\
Gtf3c2 & 2.32 & 0.008 \\
Cbfa2t2h & 2.32 & 0.002 \\
Tlk2 & 2.31 & 0.000 \\
Ids & 2.30 & 0.006 \\
LOC192950 & 2.29 & 0.005 \\
Zfp458 & 2.28 & 0.006 \\
Pitpnc1 & 2.28 & 0.000 \\
Marveld1 & 2.27 & 0.000 \\
Cntf III Zfp91 & 2.27 & 0.002 \\
& & \\
\hline
\end{tabular}


1419173_at

1437631_at

1452911_at

1417190_at

1459462_at

1434271_at

1456486_at

1417253_at

1451920_a_at

1438476_a_at

1442735 at

1459764_x_at

1434736_at

1427842_at

1417276_at

1457765_at

1448235_s_at

1450931 at

1431897_at

1449623 at

1440438_at

1459885_s_at

1445669_at

1424442_a_at

1417353_x_at

1458274_at

1453612 at

1435275_at

1455522_at

1427713_x_at

1434219_at

1452124_at

1456735_x_at

1449013 at

1443940_at

1449708_s_at aminoacylase 1

Kv channel interacting protein 4

sprouty protein with EVH-1 domain 1, related sequence

pre-B-cell colony-enhancing factor 1

Glucocorticoid induced gene

ucosidase beta 2

zinc finger protein 574

FSHD region gene 1

replication factor $\mathrm{C} 1$

chromodomain helicase DNA binding protein 4

Ornithine decarboxylase antizyme 2

Sorting nexin 10

hepatic leukemia factor

keratin associated protein 6-3

tubby-like protein 2

Proteasome (prosome, macropain) 26S subunit, non-ATPase, 14

high mobility group box 1

dedicator of cytokinesis 9

carbohydrate ( $\mathrm{N}$-acetylgalactosamine 4-0) sulfotransferase 9

hioredoxin reductase 3

WASP family 1

cytochrome c oxidase, subunit VIIc

sprouty homolog 4 (Drosophila)

praja 2, RING-H2 motif containing

small nuclear ribonucleoprotein polypeptide $A^{\prime}$

zinc finger protein 69

NIMA (never in mitosis gene a)-related expressed kinase 1

cytochrome $\mathrm{c}$ oxidase subunit Vlb polypeptide 2

Ruanine nucleotide exchange factor (GEF) 15

POU domain, class 2, transcription factor 2

stromal interaction molecule 2

ankyrin 3, epithelial /// RIKEN cDNA 2900054D09 gene

acid phosphatase-like 2

eukaryotic elongation factor-2 kinase

leucine rich repeat containing 22

checkpoint kinase 1 homolog (S. pombe)

$\begin{array}{lll}\text { Acy1 } & 2.27 & 0.002 \\ \text { Kcnip4 } & 2.26 & 0.001 \\ \text { Spred1 } & 2.26 & 0.001 \\ \text { Pbef1 } & 2.25 & 0.003 \\ \text { Gig1 } & 2.25 & 0.001 \\ \text { Gba2 } & 2.24 & 0.003 \\ \text { Zfp574 } & 2.23 & 0.010 \\ \text { Frg1 } & 2.22 & 0.000 \\ \text { Recc1 } & 2.22 & 0.005 \\ \text { Chd4 } & 2.21 & 0.010 \\ \text { Oaz2 } & 2.21 & 0.004 \\ \text { Snx10 } & 2.19 & 0.002 \\ \text { Hlf } & 2.19 & 0.002 \\ \text { Krtap6-3 } & 2.18 & 0.003 \\ \text { Tulp2 } & 2.18 & 0.009 \\ \text { Psmd14 } & 2.17 & 0.004 \\ \text { Hmgb1 III 49324: } & 2.17 & 0.003 \\ \text { Dock9 } & 2.17 & 0.007 \\ \text { Chst9 } & 2.16 & 0.008 \\ \text { Txnrd3 } & 2.16 & 0.001 \\ \text { Wasf1 } & 2.16 & 0.006 \\ \text { Cox7c } & 2.15 & 0.003 \\ \text { Spry4 } & 2.15 & 0.003 \\ \text { Pja2 } & 2.15 & 0.000 \\ \text { Snrpa1 } & 2.15 & 0.002 \\ \text { Zfp69 } & 2.14 & 0.007 \\ \text { Nek1 } & 2.13 & 0.006 \\ \text { Cox6b2 } & 2.13 & 0.008 \\ \text { Arhgef15 } & 2.13 & 0.000 \\ \text { Pou2f2 } & 2.12 & 0.004 \\ \text { Stim2 } & 2.11 & 0.000 \\ \text { Ank3 } & 2.10 & 0.004 \\ \text { Acpl2 } & 2.10 & 0.001 \\ \text { Eef2k } & 2.10 & 0.000 \\ \text { Lrrc22 } & 2.09 & 0.006 \\ \text { Chek1 } & 2.09 & 0.009 \\ \text { Hon } & & \end{array}$




$\begin{array}{ll}\text { 1418172_at } & \text { heme binding protein 1 } \\ \text { 1454928_at } & \text { scaffold attachment factor B } \\ \text { 1423704_at } & \text { lysophospholipase } 3 \\ \text { 1428130_at } & \text { lectin, mannose-binding, 1 } \\ \text { 1443838_x_at } & \text { fatty acid desaturase 2 } \\ \text { 1457767_at } & \text { Nischarin } \\ \text { 1423009_at } & \text { secretory blood group 1 } \\ \text { 1422624_at } & \text { REV1-like (S. cerevisiae) } \\ \text { 1455726_at } & \text { gene model 71, (NCBI) } \\ \text { 1443163_at } & \text { solute carrier family 39 (zinc transporter), member 2 } \\ \text { 1438039_at } & \text { HECT domain containing 1 } \\ \text { 1460285_at } & \text { integrin alpha 9 } \\ \text { 1452339_at } & \text { a disintegrin-like and metalloprotease with thrombospondin type 1 motif, } 7 \\ \text { 1447274_at } & \text { Wiskott-Aldrich syndrome protein interacting protein } \\ \text { 1422168_a_at } & \text { brain derived neurotrophic factor } \\ \text { 1423417_at } & \text { SWI/SNF related, actin dependent regulator of chromatin, subfamily c,m1 } \\ \text { 1429178_at } & \text { odd Oz/ten-m homolog } 3 \text { (Drosophila) } \\ \text { 1460239_at } & \text { tetraspanin 13 } \\ \text { 1452303_at } & \text { Rho guanine nucleotide exchange factor (GEF) 10 } \\ \text { 1424473_at } & \text { similar to polymerase (RNA) II (DNA directed) polypeptide H } \\ \text { 1422028_a_at } & \text { E26 avian leukemia oncogene 1, 5' domain } \\ \text { 1427191_at } & \text { natriuretic peptide receptor 2 } \\ \text { 1460247_a_at } & \text { S-phase kinase-associated protein 2 (p45) } \\ \text { 1422886_a_at } & \text { CDC like kinase 4 } \\ \text { 1417141_at } & \text { interferon gamma induced GTPase } \\ \text { 1417506_at } & \text { geminin } \\ \text { 1427025_at } & \text { myotubularin related protein 7 } \\ \text { 1426147_s_at } & \text { claudin 10 } \\ \text { 1455861_at } & \text { erythrocyte protein band 4.1-like } 5 \\ \text { 1417101_at } & \text { heat shock protein 2 } \\ \text { 1455065_x_at } & \text { similar to glucosamine-6-phosphate deaminase } \\ \text { 1421906_at } & \text { peroxisome proliferator activated receptor binding protein } \\ \text { 1415729_at } & \text { 3-phosphoinositide dependent protein kinase-1 } \\ \text { 1428574_a_at } & \text { chimerin (chimaerin) 2 } \\ \text { 1457711_at } & \text { RAN binding protein } 3 \\ \text { 1419393_at } & \text { ATP-binding cassette, sub-family G (WHITE), member } 5 \\ & \end{array}$

$\begin{array}{lll}\text { Hebp1 } & 2.09 & 0.001 \\ \text { Safb } & 2.09 & 0.005 \\ \text { Lypla3 } & 2.08 & 0.009 \\ \text { Lman1 } & 2.08 & 0.002 \\ \text { Fads2 } & 2.07 & 0.001 \\ \text { Nisch } & 2.07 & 0.004 \\ \text { MGl:1928893 } & 2.07 & 0.006 \\ \text { Rev1l } & 2.07 & 0.006 \\ \text { Gm71 } & 2.07 & 0.000 \\ \text { Slc39a2 } & 2.07 & 0.004 \\ \text { Hectd1 } & 2.07 & 0.005 \\ \text { Itga9 } & 2.07 & 0.004 \\ \text { Adamts7 } & 2.06 & 0.000 \\ \text { Waspip } & 2.06 & 0.006 \\ \text { Bdnf } & 2.06 & 0.009 \\ \text { Smarcc1 } & 2.04 & 0.003 \\ \text { Odz3 } & 2.04 & 0.001 \\ \text { Tspan13 } & 2.04 & 0.001 \\ \text { Arhgef10 } & 2.03 & 0.010 \\ \text { LOC381040 } & 2.03 & 0.000 \\ \text { Ets1 } & 2.03 & 0.003 \\ \text { Npr2 } & 2.03 & 0.000 \\ \text { Skp2 } & 2.03 & 0.003 \\ \text { Clk4 } & 2.03 & 0.000 \\ \text { Igtp } & 2.02 & 0.008 \\ \text { Gmnn } & 2.02 & 0.000 \\ \text { Mtmr7 } & 2.02 & 0.007 \\ \text { Cldn10 } & 2.02 & 0.007 \\ \text { Epb4.115 } & 2.02 & 0.002 \\ \text { Hspa2 } & 2.02 & 0.006 \\ \text { LOC231914 } & 2.01 & 0.005 \\ \text { Pparbp } & 2.00 & 0.004 \\ \text { Pdpk1 } & 2.00 & 0.000 \\ \text { Chn2 } & 1.99 & 0.007 \\ \text { Ranbp3 } & 1.99 & 0.003 \\ \text { Abcg5 } & 1.99 & 0.009\end{array}$


1432099_a_at

proline dehydrogenase (oxidase) 2

AT rich interactive domain 4A (Rbp1 like)

glycerol phosphate dehydrogenase 2, mitochondrial

Copping protein (actin filament), gelsolin-like

1455267_at

1442629_at

estrogen-related receptor gamma

5'-nucleotidase, cytosolic II

1448539_a_at aspartoacylase (aminoacylase) 3

1423646_at

zinc finger, $\mathrm{DHHC}$ domain containing 3

syntrophin, gamma 2

1448328_at SH3-domain binding protein 2

1449084_s_at SH3 domain protein D19

1415850_at RAS p21 protein activator 3

1452639_at

1424698_s_at

1419076_a_a

1440747_at

1427089_at

1448065 at

1417764_at

1430632 at

1425893_a_at

1418912 at

1448632_at

1426690_a_at

1423112 at

1451104_a_at

$1456011 \times$ at

1421950_at

1428512_at

1449912_at

1455002_at

1452224_at

1450657_at

1449248_at

1421236_at

ectonucleotide pyrophosphatase/phosphodiesterase 4

\section{grancalcin}

breast cancer 2

Similar to Cpo protein

cyclin $\mathrm{T} 2$

UDP-Gal:betaGIcNAc beta 1,4-galactosyltransferase, polypeptide 3

signal sequence receptor, alpha

ankyrin repeat and SOCS box-containing protein 1

fragile histidine triad gene

plexin domain containing 2

proteasome (prosome, macropain) subunit, beta type 10

sterol regulatory element binding factor 1

ubiquitin-conjugating enzyme E2D 3 (UBC4/5 homolog, yeast)

U1 small nuclear ribonucleoprotein polypeptide $A$

acetyl-Coenzyme A acyltransferase 1

prefoldin 2

basic helix-loop-helix domain containing, class B9

synovial sarcoma, $X$ member $B$, breakpoint 1

protein tyrosine phosphatase $4 a 1$

zinc finger, $\mathrm{CW}$-type with coiled-coil domain 3

peptidylprolyl isomerase $\mathrm{E}$ (cyclophilin E)

chloride channel 2

1429166 s at

Calmin

$\begin{array}{lll}\text { Prodh2 } & 1.99 & 0.000 \\ \text { Arid4a } & 1.98 & 0.008 \\ \text { Gpd2 } & 1.98 & 0.005 \\ \text { Capg } & 1.98 & 0.005 \\ \text { Esrrg } & 1.98 & 0.007 \\ \text { Nt5c2 } & 1.97 & 0.003 \\ \text { Acy3 } & 1.97 & 0.000 \\ \text { Zdhhc3 } & 1.97 & 0.002 \\ \text { Sntg2 } & 1.96 & 0.006 \\ \text { Sh3bp2 } & 1.96 & 0.001 \\ \text { Sh3d19 } & 1.96 & 0.001 \\ \text { Rasa3 } & 1.95 & 0.001 \\ \text { Enpp4 } & 1.95 & 0.005 \\ \text { Gca } & 1.94 & 0.007 \\ \text { Brca2 } & 1.94 & 0.004 \\ \text { Cpox } & 1.93 & 0.002 \\ \text { Ccnt2 } & 1.93 & 0.001 \\ \text { B4galt3 } & 1.93 & 0.010 \\ \text { Ssr1 } & 1.93 & 0.003 \\ \text { Asb1 } & 1.92 & 0.008 \\ \text { Fhit } & 1.91 & 0.001 \\ \text { Plxdc2 } & 1.91 & 0.004 \\ \text { Psmb10 } & 1.91 & 0.006 \\ \text { Srebf1 } & 1.90 & 0.002 \\ \text { Ube2d3 } & 1.90 & 0.003 \\ \text { Snrp70 } & 1.90 & 0.002 \\ \text { Acaa1 } & 1.89 & 0.001 \\ \text { Pfdn2 } & 1.89 & 0.000 \\ \text { Bhlhb9 } & 1.89 & 0.006 \\ \text { Ssxb1 } & 1.88 & 0.009 \\ \text { Ptp4a1 } & 1.88 & 0.007 \\ \text { Zcwcc3 } & 1.87 & 0.001 \\ \text { Ppie } & 1.87 & 0.005 \\ \text { Clcn2 } & 1.87 & 0.000 \\ \text { Ripk2 } & 1.86 & 0.009 \\ \text { Clmn } & 1.86 & 0.006 \\ & & \end{array}$


1450726_at

1427382 a at

1452190_at

1429888_a_at

1427596_at

1456081_a_at

1427604_a_at

1431143_x_at

1455056 at

1438417_at

1434514 at

1416072_at

1455129_at

1436197_at

1425178_s_at

1424877_a_at

1417750_a_at

1448405_a_at

1422325_at

1416639 at

1451286_s_at

1417319_at

1424061_at

1440152_x_a

1434349_at

1431505_at

1416560 at

1435645_at

1416840_at

1457635_s_at

1428974_s_at

1453836_a_at

1422806_x_at

1437067 at

1448868_at

1426606_at
$\mathrm{N}$-acylsphingosine amidohydrolase 2

suppressor of variegation 3-9 homolog 1 (Drosophila)

prolylcarboxypeptidase (angiotensinase $\mathrm{C}$ )

eat shock protein 2

$X$ (inactive)-specific transcript, antisense

acetoacetyl-CoA synthetase

ATPase, class II, type 9A

apoptosis-inducing factor (AIF)-like mitochondrion-associated inducer of death

LIM domain only 7

PWWP domain containing 2

RNA binding motif protein 15

CD34 antigen

Metadherin

CDC42 binding protein kinase gamma (DMPK-like)

serine hydroxymethyl transferase 1 (soluble)

aminolevulinate, delta-, dehydratase

mitochondrial solute carrier protein

CREBBP/EP300 inhibitory protein 1

melanoma antigen, family $A, 5$

solute carrier family 2 (facilitated glucose transporter), member 5

fusion, derived from $\mathrm{t}(12 ; 16)$ malignant liposarcoma (human)

poliovirus receptor-related 3

mannosidase, beta A, lysosomal-like

endothelial differentiation-related factor 1

valyl-tRNA synthetase 2-like

peptidyl prolyl isomerase $\mathrm{H}$

solute carrier family 13 member 3

monocyte to macrophage differentiation-associated

(gastrulation specific G12-like (zebrafish))

Nuclear receptor subfamily 3 , group $\mathrm{C}$, member 1

leucine zipper transcription factor-like 1

monoglyceride lipase

inhibitor of growth family, member 3

putative homeodomain transcription factor 2

SCAN domain-containing 1

cartilage acidic protein 1

\begin{tabular}{lll} 
Asah2 & 1.86 & 0.003 \\
Suv39h1 & 1.85 & 0.006 \\
Prcp & 1.85 & 0.000 \\
Hspb2 & 1.85 & 0.002 \\
Tsix & 1.84 & 0.004 \\
Aacs & 1.84 & 0.000 \\
Atp9a & 1.84 & 0.001 \\
Amid & 1.84 & 0.000 \\
Lmo7 & 1.84 & 0.008 \\
Pwwp2 & 1.84 & 0.003 \\
Rbm15 & 1.83 & 0.003 \\
Cd34 & 1.83 & 0.007 \\
Mtdh & 1.83 & 0.002 \\
Cdc42bpg & 1.82 & 0.001 \\
Shmt1 & 1.82 & 0.004 \\
Alad & 1.81 & 0.000 \\
MGl:1914962 & 1.81 & 0.006 \\
Cri1 & 1.81 & 0.003 \\
Magea5 & 1.81 & 0.000 \\
Slc2a5 & 1.81 & 0.002 \\
Fus & 1.81 & 0.005 \\
Pvrl3 & 1.81 & 0.009 \\
Manbal & 1.80 & 0.006 \\
Edf1 & 1.80 & 0.008 \\
Vars2l & 1.80 & 0.009 \\
Ppih & 1.80 & 0.008 \\
Slc13a3 & 1.80 & 0.008 \\
Mmd & 1.79 & 0.002 \\
Mid1ip1 & 1.79 & 0.003 \\
Nr3c1 & 1.79 & 0.001 \\
Lztfl1 & 1.78 & 0.009 \\
Mgll & 1.78 & 0.000 \\
Ing3 & 1.77 & 0.000 \\
Phtf2 & 1.77 & 0.009 \\
Scand1 & 1.76 & 0.001 \\
Crtac1 & 1.76 & 0.005 \\
\hline
\end{tabular}


1424899_at 1450420_at 1415687_a_at 1456013_x_at 1449121_at 1449486 at 1429062_at

1419104_at

1452702_at

1452257_at

1427776 a at

1419130_at

1443962_at

1452823_at

1440660_at

1416672_s_at

1435748_at

1436167 at

1454640_at

1418600 at

1426383_at

1423441_at

1457232_at

1426782_at

1450769_s_at

1423390_at

1435836 at

1416435_at

1426288_at

1429033_at

1424703_at

1455871_s_at

1426025_s_at

1458327_x_at

1426713_s_at

1449800_x_at nicotinamide nucleotide adenylyltransferase 3

stromal antigen 1

prosaposin

solute carrier family 35 , member A4

FUS interacting protein (serine-arginine rich) 1

carboxylesterase 1

kinesin family member $16 \mathrm{~B}$

abhydrolase domain containing 6

chloride channel 7

3-hydroxybutyrate dehydrogenase (heart, mitochondrial)

fibroblast growth factor receptor 4

deaminase domain containing 1

scription factor Dp 2

glutathione S-transferase kappa 1

Nuclear factor I/A

mucolipin 1

guanine deaminase

similar to Shb-like adapter protein, Shf - human

coiled-coil-helix-coiled-coil-helix domain containing 7

Kruppel-like factor 1 (erythroid)

cryptochrome 2 (photolyase-like)

transcription factor B2, mitochondrial

F-box and leucine-rich repeat protein 21

G protein-coupled receptor 125

StAR-related lipid transfer (START) domain containing 5

seven in absentia $1 A$

Pyruvate dehydrogenase kinase, isoenzyme 1

lymphotoxin $\mathrm{B}$ receptor

density lipoprotein receptor-related protein 4

golgi coiled coil 1

HemK methyltransferase family member 1

Tax1 (human T-cell leukemia virus type I) binding protein 3

lysosomal-associated protein transmembrane 5

solute carrier family 26 (sulfate transporter), member 1

glutamyl-prolyl-tRNA synthetase

PHD finger protein 7

$\begin{array}{lll}\text { Nmnat3 } & 1.76 & 0.001 \\ \text { Stag1 } & 1.76 & 0.007 \\ \text { Psap } & 1.75 & 0.009 \\ \text { Slc35a4 } & 1.75 & 0.001 \\ \text { Fusip1 } & 1.75 & 0.002 \\ \text { Ces1 } & 1.74 & 0.000 \\ \text { Kif16b } & 1.74 & 0.002 \\ \text { Abhd6 } & 1.74 & 0.005 \\ \text { Clcn7 } & 1.74 & 0.004 \\ \text { Bdh } & 1.74 & 0.003 \\ \text { Fgfr4 } & 1.74 & 0.009 \\ \text { Deadc1 } & 1.74 & 0.003 \\ \text { Tfdp2 } & 1.74 & 0.002 \\ \text { Gstk1 } & 1.73 & 0.006 \\ \text { Nfia } & 1.73 & 0.001 \\ \text { Mcoln1 } & 1.73 & 0.001 \\ \text { Gda } & 1.72 & 0.001 \\ \text { LOC435684 } & 1.72 & 0.003 \\ \text { Chchd7 } & 1.72 & 0.000 \\ \text { Klf1 } & 1.72 & 0.008 \\ \text { Cry2 } & 1.72 & 0.006 \\ \text { Tfb2m } & 1.72 & 0.008 \\ \text { Fbxl21 } & 1.72 & 0.006 \\ \text { Gpr125 } & 1.72 & 0.002 \\ \text { Stard5 } & 1.71 & 0.009 \\ \text { Siah1a } & 1.71 & 0.008 \\ \text { Pdk1 } & 1.71 & 0.008 \\ \text { Ltbr } & 1.71 & 0.000 \\ \text { Lrp4 } & 1.71 & 0.001 \\ \text { Gcc1 } & 1.71 & 0.003 \\ \text { Hemk1 } & 1.71 & 0.002 \\ \text { Tax1bp3 /I Rpl1: } & 1.70 & 0.000 \\ \text { Laptm5 } & 1.70 & 0.001 \\ \text { Slc26a1 } & 1.70 & 0.006 \\ \text { Eprs } & 1.70 & 0.000 \\ \text { Phf7 } & 1.70 & 0.001 \\ & & \end{array}$


1443757_x_at

1452235 at

1456467_s_at

1431464 a at

1451195_a_at

1456012_x_at

1456054_a_at

1416725_at

1432086_a_at

1426924_at

1459170 at

1434145_s_at

1452831_s_at

1455558_at

1428172_at

1418583_at

1448528_at

1456541 x at

1448385_at

1457024_x_at

1451602_at

1431188_a_at

1452494_s_at

1435133_at

1460597_at

1460670_at

1428367 at

1449383_at

1418091_at

1416685_s_at

1427027_a_at

1439463_x_at

1435370_a_at

1419670 at

1442519_at

1434930_at
Galactosidase, beta 1-like

mannosidase, alpha, class 1B, member 1

nemo like kinase

hosphomannomutase 2

thioredoxin domain containing 1

ribonuclease T2

pumilio 1 (Drosophila)

transcription factor 4

RIB43A domain with coiled-coils 2

membrane associated DNA binding protein

Forkhead box $\mathrm{O} 1$

serine hydrolase-like

phosphoribosyl pyrophosphate amidotransferase

gene model 114, (NCBI)

PRP39 pre-mRNA processing factor 39 homolog (yeast)

histidine triad nucleotide binding protein 3

programmed cell death 10

ATPase family, AAA domain containing $3 \mathrm{~A}$

solute carrier family 15 , member 4

solute carrier family 35 (UDP-galactose transporter), member 2

sorting nexin 6

target of myb1 homolog (chicken)

solute carrier organic anion transporter family, member 1b2

UDP-glucose ceramide glucosyltransferase

Additional sex combs like 2 (Drosophila)

RIO kinase 3 (yeast)

$\mathrm{N}$-deacetylase/N-sulfotransferase (heparan glucosaminyl) 1

adenylosuccinate synthetase like 1

cription factor CP2-like 1

\section{fibrillarin}

general transcription factor III A

high mobility group box 1

carboxylesterase 3

formiminotransferase cyclodeaminase

Dendritic cell protein GA17

two pore channel 1

\begin{tabular}{lll} 
D1Ertd161e & 1.69 & 0.009 \\
Man1b1 & 1.69 & 0.006 \\
Nlk & 1.69 & 0.004 \\
Pmm2 & 1.69 & 0.004 \\
Txndc1 & 1.68 & 0.010 \\
Rnaset2 & 1.68 & 0.004 \\
Pum1 & 1.68 & 0.007 \\
Tcf4 & 1.68 & 0.010 \\
Ribc2 & 1.68 & 0.003 \\
Mnab & 1.68 & 0.008 \\
Foxo1 & 1.68 & 0.003 \\
Serhl & 1.68 & 0.006 \\
Ppat & 1.67 & 0.003 \\
Gm114 & 1.67 & 0.004 \\
Prpf39 & 1.67 & 0.007 \\
Hint3 & 1.67 & 0.000 \\
Pdcd10 & 1.67 & 0.010 \\
Atad3a & 1.66 & 0.007 \\
Slc15a4 & 1.66 & 0.009 \\
Slc35a2 & 1.66 & 0.001 \\
Snx6 & 1.66 & 0.000 \\
Tom1 & 1.65 & 0.001 \\
Slco1b2 & 1.65 & 0.000 \\
Ugcg & 1.65 & 0.005 \\
Asxl2 & 1.65 & 0.010 \\
Riok3 & 1.65 & 0.000 \\
Ndst1 & 1.65 & 0.006 \\
Adssl1 & 1.65 & 0.004 \\
Tcfcp2l1 & 1.65 & 0.009 \\
Fbl & 1.64 & 0.005 \\
Gtf3a & 1.64 & 0.000 \\
Hmgb1 III LOC38 & 1.64 & 0.004 \\
Ces3 & 1.64 & 0.002 \\
Ftcd & 1.64 & 0.004 \\
Ga17 & 1.64 & 0.006 \\
Tpcn1 & 1.64 & 0.001 \\
& & \\
\hline
\end{tabular}


1446305_at 1417538_at 1434291_a_at 1428343_at 1417919_at 1426100_a_at 1428234_at

1435451_at

1448273_at

1452375_at

1423744 x at

1424821_at

1426051_a_at 1423898_a_at

1417061 at

1438993_a_at

1436269_s_at

1434224

1428488_at

1441733 s at

1438405_at

1421052_a_at

1429109_at

1450720 at

1429515_at

1426777_a_at

1417241

1425280_at

1451121_a_at 1423907_a_at

1451290_at

1436050_x_at

1436291_a_at

1452841 a

1451529_at

1436946 s at hypothetical gene supported by AK045626

solute carrier family 35 (CMP-sialic acid transporter), member 1

small EDRK-rich factor 1

REST corepressor 3

protein phosphatase 1 , regulatory (inhibitor) subunit 7

thymidine kinase 2 , mitochondrial

cleavage and polyadenylation specific factor 6

helicase, mus308-like (Drosophila)

glutathione synthetase

aldehyde dehydrogenase 4 family, member $A 1$

eukaryotic translation initiation factor 2 , subunit 3 , structural gene X-linked

Nedd 4 family interacting protein 1

centromere autoantigen B

thyroid hormone receptor interactor 12

solute carrier family 40 (iron-regulated transporter), member 1

ATPase, $\mathrm{H}+$ transporting, $\mathrm{V} 1$ subunit $\mathrm{D}$

protease, serine, 25

transducin (beta)-like 2

phosphatidylinositol glycan, class $\mathrm{K}$

nucleoporin 153

fibroblast growth factor 7

spermine synthase

ring finger protein 184

acid phosphatase 1 , soluble

ubiquitin protein ligase E3 component n-recognin 2

Wiskott-Aldrich syndrome-like (human)

EST X83328

leukocyte receptor cluster (LRC) member 1

glioma tumor suppressor candidate region gene 2

$\mathrm{NADH}$ dehydrogenase (ubiquinone) Fe-S protein 8

microtubule-associated protein 1 light chain 3 alpha

hairy and enhancer of split 6 (Drosophila)

dihydropyrimidinase

phosphoglucomutase 2-like 1

small glutamine-rich tetratricopeptide repeat (TPR)-containing, beta

guanine nucleotide binding protein (G protein), gamma 5 subunit

$\begin{array}{lll}\text { LOC432657 } & 1.63 & 0.001 \\ \text { Slc35a1 } & 1.63 & 0.000 \\ \text { Serf1 } & 1.63 & 0.010 \\ \text { Rcor3 } & 1.63 & 0.000 \\ \text { Ppp1r7 } & 1.63 & 0.000 \\ \text { Tk2 } & 1.63 & 0.001 \\ \text { Cpsf6 } & 1.63 & 0.002 \\ \text { MGl:2176740 } & 1.63 & 0.006 \\ \text { Gss } & 1.62 & 0.001 \\ \text { Aldh4a1 } & 1.62 & 0.001 \\ \text { Eif2s3x } & 1.62 & 0.003 \\ \text { Ndfip1 } & 1.61 & 0.001 \\ \text { Cenpb } & 1.61 & 0.004 \\ \text { Trip12 } & 1.61 & 0.001 \\ \text { Slc40a1 } & 1.61 & 0.001 \\ \text { Atp6v1d } & 1.61 & 0.005 \\ \text { Prss25 } & 1.61 & 0.004 \\ \text { Tbl2 } & 1.61 & 0.006 \\ \text { Pigk } & 1.60 & 0.000 \\ \text { Nup153 } & 1.60 & 0.000 \\ \text { Fgf7 } & 1.60 & 0.003 \\ \text { Sms } & 1.60 & 0.003 \\ \text { Rnf184 } & 1.60 & 0.009 \\ \text { Acp1 } & 1.60 & 0.003 \\ \text { Ubr2 } & 1.60 & 0.002 \\ \text { Wasl } & 1.60 & 0.006 \\ \text { X83328 } & 1.60 & 0.002 \\ \text { Leng1 } & 1.60 & 0.006 \\ \text { Gltscr2 } & 1.59 & 0.000 \\ \text { Ndufs8 } & 1.59 & 0.000 \\ \text { Map1lc3a } & 1.59 & 0.001 \\ \text { Hes6 } & 1.59 & 0.003 \\ \text { Dpys } & 1.59 & 0.005 \\ \text { Pgm2l1 } & 1.59 & 0.004 \\ \text { Sgtb } & 1.59 & 0.007 \\ \text { Gng5 } & 1.59 & 0.004 \\ & & \\ \text { Nin } & & \end{array}$


1453136_at

F-box protein 30

Fbxo30 $\quad 1.59$

1423442 a at F-box and WD-40 domain protein 2

Fbxw2

1419105_at

nuclear receptor subfamily 1 , group $\mathrm{H}$, member 4

159

1436724 a at

1449055_x_at poly( $(\mathrm{rC})$ binding protein 4

1429052 at protein tyrosine phosphatase, receptor type, D

1439481_at_Importin 9

1425927_a_at activating transcription factor 5

1453641

breast carcinoma amplified sequence 1

1452309_at cingulin-like 1

1453071_s_at KDEL (Lys-Asp-Glu-Leu) containing 2

1450556_at spectrin beta 1

1460642_at Tnf receptor associated factor 4

1423350_at suppressor of cytokine signaling 5

1421379_at zinc finger protein 354B

1417932 at interleukin 18

1449506_a_at eukaryotic translation elongation factor 1 delta

1439251 at

1425068_a_at

1416657 at

Iduronidase, alpha-L-

testis expressed gene 264

thymoma viral proto-oncogene 1

1417694_at growth factor receptor bound protein 2-associated protein 1

1460652 at

Estrogen related receptor, alpha

1424604_s_at sulfatase modifying factor 1

1426675_at translocase of outer mitochondrial membrane 70 homolog A (yeast)

1443779 s at Mblk1-related protein-2

1452608_at c-myc binding protein

1449067 at solute carrier family 2 (facilitated glucose transporter), member 2

1416954_at solute carrier family 25 member 10

1418448_at Harvey rat sarcoma oncogene, subgroup R

1419395_at cytosolic acetyl-CoA hydrolase

1416523_at

1416942_at

ribonuclease, RNase A family, 1 (pancreatic)

1428410_at

type 1 tumor necrosis factor receptor shedding aminopeptidase regulator

Mak3 homolog (S. cerevisiae)

1420476 a at nucleosome assembly protein 1-like 1

1435746_at

serine/arginine-rich protein specific kinase 2

1422490 at

BCL2/adenovirus E1B 19kDa-interacting protein 1, NIP2 
1422516_a_at fibroblast growth factor (acidic) intracellular binding protein

brain acyl-CoA hydrolase

1448276_at tetraspanin 4

1426773_at mitofusin 1

1416418_at gamma-aminobutyric acid $(\mathrm{GABA}(\mathrm{A}))$ receptor-associated protein-like 1

1439237_a_at

1424736

1441682_s_at

1418444 a at

1416616_s_at

1454109_a_at

1424080_at

1453069_at

1452506_a_at

1459476_s_at

1421945_a_at

1419197_x_at

1419526 at

1420368_at

1416618_at

1435534_a_at

1454840 at

1416037_a_at

1424333_at

1416593 at

1453146_at

1448131_at

1448154_at

1428454_at

1428224_at

1434630_at

1422568 at

1448702_at

1459678_at

slingshot homolog 1 (Drosophila)

eukaryotic translation elongation factor 2

exportin, tRNA (nuclear export receptor for tRNAs)

membrane interacting protein of RGS16

caseinolytic protease, ATP-dependent, proteolytic subunit homolog (E. coli)

phosphatidylserine receptor

decapping enzyme, scavenge

phosphatidylinositol 3-kinase, catalytic, beta polypeptide

integrin-linked kinase-associated serine/threonine phosphatase $2 \mathrm{C}$

cysteine and glycine-rich protein 2 binding protein

brix domain containing 1

hepcidin antimicrobial peptide 1

Gardner-Rasheed feline sarcoma viral (Fgr) oncogene homolog

density-regulated protein

protoporphyrinogen oxidase

translocase of outer mitochondrial membrane 20 homolog (yeast)

methylcrotonoyl-Coenzyme A carboxylase 2 (beta)

chaperonin subunit 2 (beta)

RNA (guanine-9-) methyltransferase domain containing 1

glutaredoxin 1 (thioltransferase)

GTPase activating protein and VPS9 domains 1

mitofusin 2

$\mathrm{N}$-myc downstream regulated gene 2

breast carcinoma amplified sequence 3

heterogeneous nuclear ribonucleoprotein D-like

ankyrin repeat domain 28

nuclear distribution gene E-like homolog 1 (A. nidulans)

immediate early response 3 interacting protein 1

hypothetical LOC497255

\begin{tabular}{lll} 
Fibp & 1.53 & 0.002 \\
Il6st & 1.53 & 0.005 \\
Rsafd1 & 1.53 & 0.003 \\
MGl:1917275 & 1.53 & 0.006 \\
Tspan4 & 1.53 & 0.000 \\
Mfn1 & 1.53 & 0.007 \\
Gabarapl1 & 1.52 & 0.000 \\
Ssh1 & 1.52 & 0.004 \\
Eef2 & 1.52 & 0.005 \\
Xpot & 1.52 & 0.001 \\
MGl:1891827 & 1.52 & 0.008 \\
Clpp & 1.52 & 0.002 \\
Ptdsr & 1.51 & 0.002 \\
Dcps & 1.51 & 0.007 \\
Pik3cb & 1.51 & 0.000 \\
Ilkap & 1.50 & 0.001 \\
Csrp2bp & 1.50 & 0.009 \\
Bxdc1 & 1.50 & 0.000 \\
Hamp1 & 1.50 & 0.002 \\
Fgr & 1.50 & 0.006 \\
Denr & 1.50 & 0.001 \\
Ppox & 1.50 & 0.001 \\
Tomm20 & 1.50 & 0.002 \\
Mccc2 & 1.50 & 0.001 \\
Cct2 & 1.50 & 0.000 \\
Rg9mtd1 & 1.50 & 0.010 \\
Glrx1 & 1.50 & 0.010 \\
Gapvd1 & 1.49 & 0.002 \\
Mfn2 & 1.49 & 0.007 \\
Ndrg2 & 1.49 & 0.001 \\
Bcas3 & 1.49 & 0.007 \\
Hnrpdl & 1.49 & 0.005 \\
Ankrd28 & 1.49 & 0.003 \\
Ndel1 & 1.49 & 0.002 \\
ler3ip1 & 1.49 & 0.006 \\
LOC497255 & 1.49 & 0.008 \\
& & \\
\hline
\end{tabular}




$\begin{array}{ll}\text { 1454795_at } & \text { Cobl-like 1 } \\ \text { 1428149_at } & \text { coronin } 7 \\ \text { 1418698_a_at } & \text { ferrochelatase } \\ \text { 1448864_at } & \text { SNF related kinase } \\ \text { 1428248_at } & \text { nuclear transcription factor, X-box binding 1 } \\ \text { 1423783_at } & \text { torsin family 2, member A } \\ \text { 1424319_at } & \text { oral cancer overexpressed 1 } \\ \text { 1434937_at } & \text { pam, highwire, rpm 1 } \\ \text { 1455570_x_at } & \text { calponin 3, acidic } \\ \text { 1433649_at } & \text { amine oxidase, flavin containing 1 } \\ \text { 1416155_at } & \text { high mobility group box 3 } \\ \text { 1434412_x_at } & \text { STIP1 homology and U-Box containing protein 1 } \\ \text { 1453169_a_at } & \text { general transcription factor II H, polypeptide 1 } \\ \text { 1417605_s_at } & \text { calcium/calmodulin-dependent protein kinase I } \\ \text { 1434113_a_at } & \text { XPMC2 prevents mitotic catastrophe 2 homolog (Xenopus laevis) } \\ \text { 1429237_at } & \text { syntaxin 16 } \\ \text { 1459329_at } & \text { Tetratricopeptide repeat domain } 7 \\ \text { 1451576_at } & \text { protein kinase, DNA activated, catalytic polypeptide } \\ \text { 1450649_at } & \text { guanine nucleotide binding protein (G protein), gamma 10 } \\ \text { 1455252_at } & \text { Tuberous sclerosis 1 } \\ \text { 1423047_at } & \text { toll interacting protein } \\ \text { 1422469_at } & \text { TANK-binding kinase 1 } \\ \text { 1450841_at } & \text { intergral membrane protein 1 } \\ \text { 1424981_at } & \text { neurolysin (metallopeptidase M3 family) } \\ \text { 1429001_at } & \text { pirin } \\ \text { 1455696_a_at } & \text { PRP4 pre-mRNA processing factor 4 homolog B (yeast) } \\ \text { 1454836_at } & \text { transmembrane protein 18 } \\ \text { 1436405_at } & \text { Dedicator of cytokinesis 4 } \\ \text { 1454781_x_at } & \text { COMM domain containing 9 } \\ \text { 1420842_at } & \text { protein tyrosine phosphatase, receptor type, F } \\ \text { 1456777_at } & \text { maltase-glucoamylase } \\ \text { 1434394_at } & \text { Bcl3 binding protein } \\ \text { 1460308_a_at } & \text { immature colon carcinoma transcript 1 } \\ \text { 1454802_x_at } & \text { ariadne homolog } 2 \text { (Drosophila) } \\ \text { 1428169_at } & \text { APG16 autophagy 16-like (S. cerevisiae) } \\ \text { 1448460_at } & \text { activin A receptor, type 1 } \\ & \end{array}$

$\begin{array}{lll}\text { Cobll1 } & 1.48 & 0.003 \\ \text { Coro7 } & 1.48 & 0.001 \\ \text { Fech } & 1.48 & 0.001 \\ \text { Snrk } & 1.48 & 0.001 \\ \text { Nfx1 } & 1.48 & 0.001 \\ \text { Tor2a } & 1.48 & 0.003 \\ \text { Oraov1 } & 1.48 & 0.004 \\ \text { Phr1 } & 1.48 & 0.003 \\ \text { Cnn3 } & 1.48 & 0.003 \\ \text { Aof1 } & 1.48 & 0.000 \\ \text { Hmgb3 } & 1.47 & 0.006 \\ \text { Stub1 } & 1.47 & 0.008 \\ \text { Gtf2h1 } & 1.47 & 0.008 \\ \text { Camk1 } & 1.47 & 0.003 \\ \text { Xpmc2h } & 1.47 & 0.000 \\ \text { Stx16 } & 1.47 & 0.004 \\ \text { Ttc7 } & 1.47 & 0.001 \\ \text { Prkdc } & 1.47 & 0.009 \\ \text { Gng10 } & 1.47 & 0.005 \\ \text { Tsc1 } & 1.47 & 0.004 \\ \text { Tollip } & 1.47 & 0.010 \\ \text { Tbk1 } & 1.47 & 0.001 \\ \text { Itm1 } & 1.47 & 0.000 \\ \text { Nln } & 1.47 & 0.002 \\ \text { Pir } & 1.47 & 0.000 \\ \text { Prpf4b } & 1.47 & 0.004 \\ \text { Tmem18 } & 1.46 & 0.005 \\ \text { Dock4 } & 1.46 & 0.003 \\ \text { Commd9 } & 1.46 & 0.007 \\ \text { Ptprf } & 1.46 & 0.002 \\ \text { Mgam } & 1.45 & 0.003 \\ \text { MGl:2684414 } & 1.45 & 0.002 \\ \text { Ict1 } & 1.45 & 0.004 \\ \text { Arih2 } & 1.45 & 0.005 \\ \text { Apg16I } & 1.45 & 0.002 \\ \text { Acvr1 } & 1.45 & 0.009\end{array}$


1423589_at

1436834 x at

1440217_at

1460363_at

1435543_at

1434111_at

1425096_a_at

1460213_at

1426706_s_at

1430875_a_at

1416252 at

1450816_at

1418305_s_at

1418668_at

1455073_at

1423770_at

1425142_a_a

1422807 at

1452033_at

1422534 at

1437236_a_at

1418992_at

1447655_x_at

1455011 at

1452095_a_at

1420157_s_at

1418656 at

1423890_x_at

1429168_at

1424358_at

1417591_at

1448921_a_at

1437131_x_at

1451397 a

1450826_a_at

1448592_at actin related protein 2/3 complex, subunit 4

malate dehydrogenase 1, NAD (soluble)

similar to hypothetical protein FLJ39743

(n)

Adenomatosis polyposis col

latrophilin 2

pentatricopeptide repeat domain 1

golgi autoantigen, golgin subfamily a, 4

xylulokinase homolog $(\mathrm{H}$. influenzae)

PAK1 interacting protein 1

serine/threonine kinase 38

polymerase (DNA directed), gamma 2 , accessory subunit

(H/ACA small nucleolar RNPs)

butyryl Coenzyme A synthetase 1

cytidine and dCMP deaminase domain containing 1

transmembrane channel-like gene family 6

heterogeneous nuclear ribonucleoprotein $\mathrm{D}$

ADP-ribosylation factor 5

GLE1 RNA export mediator-like (yeast

cytochrome P450, family 51

zinc finger protein 110

coagulation factor $X$

SRY-box containing gene 6

StAR-related lipid transfer (START) domain containing 4

histocompatibility 47

ATP-binding cassette, sub-family F (GCN20), member 1

LSM5 homolog, U6 small nuclear RNA associated (S. cerevisiae)

ATPase, $\mathrm{Na}+/ \mathrm{K}+$ transporting, beta 1 polypeptide

(POZ) domain containing 4

ubiquitin-conjugating enzyme E2E 2 (UBC4/5 homolog, yeast)

prostaglandin E synthase 2

mitochondrial ribosomal protein $\mathrm{S} 9$

mitochondrial ribosomal protein L1

trinucleotide repeat containing 15

serum amyloid $A 3$

cartilage associated protein

\begin{tabular}{lll} 
Arpc4 & 1.45 & 0.001 \\
Mdh1 & 1.45 & 0.010 \\
LOC434197 & 1.45 & 0.005 \\
Tnrc6c & 1.45 & 0.003 \\
Apc & 1.44 & 0.002 \\
Lphn2 & 1.44 & 0.005 \\
Ptcd1 & 1.44 & 0.002 \\
Golga4 & 1.44 & 0.009 \\
Xylb & 1.44 & 0.005 \\
Pak1ip1 & 1.44 & 0.005 \\
Stk38 & 1.44 & 0.000 \\
Polg2 & 1.44 & 0.001 \\
Nola1 & 1.43 & 0.006 \\
Bucs1 & 1.43 & 0.006 \\
Cdadc1 & 1.43 & 0.002 \\
Tmc6 & 1.43 & 0.004 \\
Hnrpd & 1.43 & 0.001 \\
Arf5 & 1.43 & 0.000 \\
Gle1l & 1.43 & 0.006 \\
Cyp51 & 1.43 & 0.009 \\
Zfp110 & 1.43 & 0.007 \\
F10 & 1.43 & 0.002 \\
Sox6 & 1.43 & 0.001 \\
Stard4 & 1.43 & 0.004 \\
H47 & 1.42 & 0.007 \\
Abcf1 & 1.42 & 0.000 \\
Lsm5 & 1.42 & 0.006 \\
Atp1b1 & 1.42 & 0.009 \\
Btbd4 & 1.42 & 0.009 \\
Ube2e2 & 1.42 & 0.000 \\
Ptges2 & 1.42 & 0.001 \\
Mrps9 & 1.42 & 0.002 \\
Mrpl11 & 1.41 & 0.002 \\
Tnrc15 & 1.41 & 0.008 \\
Saa3 & 1.41 & 0.005 \\
Crtap & 1.41 & 0.004 \\
& & \\
\hline
\end{tabular}




$\begin{array}{ll}\text { 1424760_a_at } & \text { SET and MYND domain containing } 2 \\ \text { 1429778_at } & \text { optineurin } \\ \text { 1450921_at } & \text { aprataxin } \\ \text { 1457672_at } & \text { chromodomain helicase DNA binding protein } 9 \\ \text { 1416202_at } & \text { B-cell receptor-associated protein 37 } \\ \text { 1423684_at } & \text { heterogeneous nuclear ribonucleoprotein K } \\ \text { 1429787_x_at } & \text { ZW10 interactor } \\ \text { 1449374_at } & \text { pipecolic acid oxidase } \\ \text { 1460395_at } & \text { NudC domain containing 3 } \\ \text { 1456109_a_at } & \text { mitochondrial ribosomal protein S15 } \\ \text { 1422000_at } & \text { aldo-keto reductase family 1, member C12 } \\ \text { 1435787_at } & \text { protein phosphatase 1 (formerly 2C)-like } \\ \text { 1423295_at } & \text { transmembrane 9 superfamily member 2 } \\ \text { 1426870_at } & \text { F-box only protein 33 } \\ \text { 1417558_at } & \text { Fyn proto-oncogene } \\ \text { 1416271_at } & \text { PERP, TP53 apoptosis effector } \\ \text { 1424103_at } & \text { APG4 (ATG4) autophagy-related homolog B (S. cerevisiae) } \\ \text { 1453564_a_at } & \text { vacuolar protein sorting 24 (yeast) } \\ \text { 1418503_at } & \text { heat shock protein 9A } \\ \text { 1427945_at } & \text { dihydropyrimidine dehydrogenase } \\ \text { 1451247_at } & \text { major facilitator superfamily domain containing 1 } \\ \text { 1452289_a_at } & \text { ring finger protein 135 } \\ \text { 1433461_at } & \text { splicing factor 3b, subunit 2 } \\ \text { 1452434_s_at } & \text { DiGeorge syndrome critical region gene 6 } \\ \text { 1426403_at } & \text { ARP1 actin-related protein 1 homolog B (yeast) } \\ \text { 1439012_a_at } & \text { deoxycytidine kinase } \\ \text { 1451728_at } & \text { WD repeat domain 13 } \\ \text { 1438510_a_at } & \text { histidyl-tRNA synthetase } \\ \text { 1435347_at } & \text { staufen (RNA binding protein) homolog 1 (Drosophila) } \\ \text { 1448692_at } & \text { ubiquilin 4 } \\ \text { 1424104_at } & \text { GCIP-interacting protein p29 } \\ \text { 1438096_a_at } & \text { deoxythymidylate kinase } \\ \text { 1455940_x_at } & \text { WD repeat domain } 6 \\ \text { 1460631_at } & \text { O-linked N-acetylglucosamine (GlcNAc) transferase } \\ \text { 1456712_at } & \text { Mblk1-related protein-1 } \\ \text { 1434816_at } & \text { vacuolar protein sorting 33A (yeast) } \\ & \end{array}$

\begin{tabular}{lll} 
Smyd2 & 1.41 & 0.002 \\
Optn & 1.41 & 0.001 \\
Aptx & 1.41 & 0.002 \\
Chd9 & 1.41 & 0.000 \\
Bcap37 & 1.41 & 0.006 \\
Hnrpk & 1.41 & 0.001 \\
Zwint & 1.41 & 0.000 \\
Pipox & 1.41 & 0.001 \\
Nudcd3 & 1.41 & 0.006 \\
Mrps15 & 1.40 & 0.008 \\
Akr1c12 & 1.40 & 0.008 \\
Ppm1l & 1.40 & 0.001 \\
Tm9sf2 & 1.40 & 0.002 \\
Fbxo33 & 1.40 & 0.004 \\
Fyn & 1.40 & 0.006 \\
Perp & 1.40 & 0.000 \\
Apg4b & 1.40 & 0.010 \\
Vps24 & 1.40 & 0.002 \\
Hspa9a & 1.39 & 0.000 \\
Dpyd & 1.39 & 0.005 \\
Mfsd1 & 1.39 & 0.001 \\
Rnf135 & 1.39 & 0.000 \\
Sf3b2 & 1.39 & 0.007 \\
Dgcr6 & 1.38 & 0.000 \\
Actr1b & 1.38 & 0.010 \\
Dck & 1.38 & 0.008 \\
Wdr13 & 1.38 & 0.000 \\
Hars & 1.38 & 0.001 \\
Stau1 & 1.38 & 0.005 \\
Ubqln4 & 1.38 & 0.006 \\
MGl:1915842 & 1.38 & 0.001 \\
Dtymk & 1.38 & 0.008 \\
Wdr6 & 1.38 & 0.002 \\
Ogt & 1.38 & 0.000 \\
MGl:2651932 & 1.38 & 0.006 \\
Vps33a & 1.38 & 0.002 \\
\hline & & \\
\hline Jys
\end{tabular}


1428511_at

1424000_a_at

1451005_at

1416742_at

1453215_at

1460703_at

1435887_at

1427901_at

1423701_at

1455007_s_at

1429615 at

1429627_at

1423757_x_at

1427670_a_at

1434062 at

1450982_at

1448869_a_at

1427214 at

1449316_at

1438004 at

1433824_x_at

1433781_a_at

1448887_x_at

1418152 at

1435398_at

1417449_at

1452020 a at

1438368_a_at

1437478_s_at

1449095_at

1422732_at

1452149_at

1427200_at

1418763 at

1418566_s_at

1454060_a_at phosphorylase kinase, gamma 2 (testis)

ribosomal protein S11

SMT3 suppressor of mif two 3 homolog 1 (yeast)

(

ribonuclease, RNase A family, 10 (non-active)

activating signal cointegrator 1 complex subunit 1

serine (or cysteine) proteinase inhibitor, clade A member 11

mitochondrial ribosomal protein $\mathrm{S} 18 \mathrm{C}$

Coenzyme A synthase

glutamic pyruvate transaminase (alanine aminotransferase) 2

zinc finger protein 91

peptidylprolyl isomerase (cyclophilin)-like 3

insulin-like growth factor binding protein 4

transcription factor 12

RAB GTPase activating protein 1-like

solute carrier family 9 (sodium/hydrogen exchanger), isoform 3 regulator 1

mitochondrial ribosomal protein S16

agmatine ureohydrolase (agmatinase)

cytochrome P450, family 4, subfamily f, polypeptide 15

polymerase (DNA directed) sigma

G-rich RNA sequence binding factor 1

claudin 12

fractured callus expressed transcript 1

nucleosome binding protein 1

syntaxin binding protein 5 (tomosyn)

peroxisomal acyl-CoA thioesterase 1

Cd27 binding protein (Hindu God of destruction)

matrin 3

EF hand domain containing 2

vacuolar protein sorting 54 (yeast)

polymerase (DNA-directed), delta interacting protein 2

ubiquitin protein ligase E3B

zinc finger, RAN-binding domain containing 1

nitrilase family, member 2

NudC domain containing 2

neuroblastoma ras oncogene

\begin{tabular}{lll} 
Phkg2 & 1.38 & 0.001 \\
Rps11 & 1.38 & 0.001 \\
Sumo1 & 1.38 & 0.001 \\
Cfdp1 & 1.38 & 0.007 \\
Rnase10 & 1.38 & 0.008 \\
Ascc1 & 1.37 & 0.005 \\
Serpina11 & 1.37 & 0.001 \\
Mrps18c & 1.37 & 0.001 \\
Coasy & 1.37 & 0.001 \\
Gpt2 & 1.37 & 0.008 \\
Zfp91 & 1.37 & 0.003 \\
Ppil3 & 1.37 & 0.003 \\
Igfbp4 & 1.37 & 0.004 \\
Tcf12 & 1.37 & 0.004 \\
Rabgap1l & 1.37 & 0.001 \\
Slc9a3r1 & 1.37 & 0.001 \\
Mrps16 & 1.37 & 0.008 \\
Agmat & 1.37 & 0.009 \\
Cyp4f15 & 1.37 & 0.001 \\
Pols & 1.36 & 0.001 \\
Grsf1 & 1.36 & 0.002 \\
Cldn12 & 1.36 & 0.003 \\
Fxc1 & 1.36 & 0.010 \\
Nsbp1 & 1.36 & 0.000 \\
Stxbp5 & 1.36 & 0.003 \\
Pte1 & 1.36 & 0.010 \\
MGl:1353606 & 1.36 & 0.004 \\
Matr3 & 1.36 & 0.007 \\
Efhd2 & 1.36 & 0.009 \\
Vps54 & 1.36 & 0.000 \\
Poldip2 & 1.36 & 0.001 \\
Ube3b & 1.36 & 0.008 \\
Zranb1 & 1.35 & 0.005 \\
Nit2 & 1.35 & 0.007 \\
Nudcd2 & 1.35 & 0.007 \\
Nras & 1.35 & 0.001 \\
& & \\
\hline
\end{tabular}


1460184_at

1416765 s at

1419976_s_at

1448659_at

1417368_s_at

1424840 at

1428428_at

1448563_at

1427071_at

1417081_a_at

1428111 at

1434782_at

1419546_at

1418257_at

1429005_at

1459098_at

1423731_at

1452000_s_at

1452327_at

1416345 at

1428131_a_at

1453271 at

1422869_at

1449849_a_at

1451511_a

1437014_x_at

1424898 at

1416904_at

1424355_a_at

1451274_at

1448321_at

1433886_at

1452782_a_at

1424723_s_at

1424285_s_at

1439432_x_at
L-3-hydroxyacyl-Coenzyme A dehydrogenase, short chain

mitochondria-associated protein

nuclear factor of activated T-cells, cytoplasmic, calcineurin-dependent 3

caspase 7

NADH dehydrogenase (ubiquinone) 1 alpha subcomplex, 2

okinase

Williams Beuren syndrome chromosome region 21

prohibitin

F-box protein 42

synaptogyrin 2

solute carrier family 38 , member 4

ubiquitin specific protease 42

ATPase, $\mathrm{H}+$ transporting, $\mathrm{V} 1$ subunit $\mathrm{C}$, isoform 1

solute carrier family 12 , member 7

malignant fibrous histiocytoma amplified sequence 1

Dystonin

aldehyde dehydrogenase 16 family, member A1

seryl-aminoacyl-tRNA synthetase 1

IQ motif and Sec7 domain 1

Q

CDC42 small effector 1

PHD finger protein 14

c-mer proto-oncogene tyrosine kinase

F-box and leucine-rich repeat protein 6

3-hydroxyisobutyryl-Coenzyme A hydrolase

Peroxiredoxin 1

solute carrier family 10 (sodium/bile acid cotransporter family), member 1

muscleblind-like 1 (Drosophila)

transcriptional regulator, SIN3B (yeast)

oxoglutarate dehydrogenase (lipoamide)

SPARC related modular calcium binding 1

eukaryotic translation initiation factor 2B, subunit 5 epsilon

thioredoxin 2

cleavage stimulation factor, 3' pre-RNA, subunit 3

ADP-ribosylation factor-like 6 interacting protein 4

mortality factor 4 like 2

\begin{tabular}{lll} 
Hadhsc & 1.35 & 0.001 \\
MGl:1913699 & 1.35 & 0.001 \\
Nfatc3 & 1.35 & 0.000 \\
Casp7 & 1.34 & 0.009 \\
Ndufa2 & 1.34 & 0.002 \\
Rbks & 1.34 & 0.008 \\
Wbscr21 & 1.34 & 0.006 \\
Phb & 1.34 & 0.001 \\
Fbxo42 & 1.34 & 0.004 \\
Syngr2 & 1.34 & 0.000 \\
Slc38a4 & 1.33 & 0.000 \\
Usp42 & 1.33 & 0.002 \\
Atp6v1c1 & 1.33 & 0.010 \\
Slc12a7 & 1.33 & 0.000 \\
Mfhas1 & 1.33 & 0.002 \\
Dst & 1.33 & 0.009 \\
Aldh16a1 & 1.33 & 0.002 \\
Sars1 & 1.33 & 0.009 \\
Iqsec1 & 1.33 & 0.001 \\
Timm8a & 1.33 & 0.007 \\
Cdc42se1 & 1.33 & 0.004 \\
Phf14 & 1.32 & 0.002 \\
Mertk & 1.32 & 0.006 \\
Fbxl6 & 1.32 & 0.006 \\
Hibch & 1.32 & 0.000 \\
Prdx1 & 1.32 & 0.005 \\
Slc10a1 & 1.32 & 0.004 \\
Mbnl1 & 1.32 & 0.006 \\
Sin3b & 1.32 & 0.010 \\
Ogdh & 1.32 & 0.009 \\
Smoc1 & 1.32 & 0.002 \\
Eif2b5 & 1.31 & 0.005 \\
Txn2 & 1.31 & 0.010 \\
Cstf3 & 1.31 & 0.009 \\
Arl6ip4 & 1.31 & 0.007 \\
Morf4l2 & 1.31 & 0.005 \\
& & \\
\hline
\end{tabular}


1452039_a_at

1425021_a_a

1416637_at

1422603_at

1418845_at

1416647_at

1416831_at

1433612_at

1416533_at

1455746_at

1437301 a at

1451825_a_at

1429830_a_at

1431375_s_at

1448723 at

1417870_x_at

1428917_at

1421148 a at

1428029_a_at

1448418 s at

1456604_a_at

1460389 at

1423255_at

1422627_a_a

1454760_at

1423271_at

1434791 at

1426823_s_at

1433750_at

1451351_at

1424441_at

1450937_at

1426501_a_at

1417045 at

1452209_at

1454753_at
Brca1 associated protein 1

peroxisome biogenesis factor 16

solute carrier family 4 (anion exchanger), member 2

ribonuclease, RNase A family 4

protein C

branched chain ketoacid dehydrogenase E1, alpha polypeptide

neuraminidase 1

adaptor-related protein complex 2, sigma 1 subunit

EGL nine homolog 2 (C. elegans)

kinesin family member $13 A$

dishevelled, dsh homolog 1 (Drosophila)

coatomer protein complex, subunit zeta 1

CD59a antigen

parvin, alpha

retinol dehydrogenase 7

cathepsin Z

syntaxin 17

Tial1 cytotoxic granule-associated RNA binding protein-like 1

$\mathrm{H} 2 \mathrm{~A}$ histone family, member $\mathrm{V}$

WD repeat domain 23

protein-L-isoaspartate (D-aspartate) O-methyltransferase 1

cyclin-dependent kinase 8

ATPase, $\mathrm{H}+$ transporting, $\mathrm{V} 1$ subunit $\mathrm{G}$ isoform 1

McKusick-Kaufman syndrome protein

HIV TAT specific factor 1

gap junction membrane channel protein beta 2

ATPase, $\mathrm{H}+$ transporting, lysosomal V0 subunit a isoform 2

proteasome (prosome, macropain) activator subunit 4

solute carrier family 31 , member 1

tetratricopeptide repeat domain 13

solute carrier family 27 (fatty acid transporter), member 4

lin 7 homolog $c$ (C. elegans)

Traf2 binding protein

$\mathrm{BH} 3$ interacting domain death agonist

plakophilin 4

arginyl aminopeptidase (aminopeptidase B)-like 1

\begin{tabular}{lll} 
Bap1 & 1.31 & 0.001 \\
Pex16 & 1.31 & 0.002 \\
Slc4a2 & 1.31 & 0.007 \\
Rnase4 & 1.31 & 0.005 \\
Proc & 1.30 & 0.000 \\
Bckdha & 1.30 & 0.006 \\
Neu1 & 1.30 & 0.002 \\
Ap2s1 & 1.30 & 0.001 \\
Egln2 & 1.30 & 0.001 \\
Kif13a & 1.30 & 0.002 \\
Dvl1 & 1.30 & 0.009 \\
Copz1 & 1.30 & 0.007 \\
Cd59a & 1.30 & 0.003 \\
Parva & 1.30 & 0.004 \\
Rdh7 & 1.30 & 0.002 \\
Ctsz & 1.30 & 0.006 \\
Stx17 & 1.29 & 0.003 \\
Tial1 & 1.29 & 0.005 \\
H2afv & 1.29 & 0.002 \\
Wdr23 & 1.29 & 0.004 \\
Pcmt1 & 1.29 & 0.004 \\
Cdk8 & 1.29 & 0.005 \\
Atp6v1g1 & 1.29 & 0.006 \\
Mkks & 1.29 & 0.007 \\
Htatsf1 & 1.29 & 0.001 \\
Gjb2 & 1.29 & 0.000 \\
Atp6v0a2 & 1.29 & 0.005 \\
Psme4 & 1.28 & 0.005 \\
Slc31a1 & 1.28 & 0.007 \\
Ttc13 & 1.28 & 0.008 \\
Slc27a4 & 1.28 & 0.010 \\
Lin7c & 1.28 & 0.005 \\
MGl:2182965 & 1.28 & 0.004 \\
Bid & 1.28 & 0.002 \\
Pkp4 & 1.27 & 0.004 \\
Rnpepl1 & 1.27 & 0.000 \\
\hline
\end{tabular}


1417183_at 1417966_at 1451848_a_at 1438560_x_at 1420525_a_at 1429048_at 1439268_x_at 1437009_a_at 1451088_a_at 1448542_at

1449244 at 1453156_s_at 1423680_at 1422032_a_at 1424088 at 1450714 at 1451205_at 1424746 at 1456628_x_at 1423894 a at 1423687_a_at 1424078_s_at 1451366_at

1427578_a_at 1436609_a_at 1423042_at 1448149 at 1448225_at 1427918_a_at 1421772_a_at 1431619_a_at 1448253_at

1448653_at 1416738_at

1424753_at 1415869 a at
DnaJ (Hsp40) homolog, subfamily A, member 2

mitochondrial ribosomal protein L39

crystallin, zeta

chaperonin subunit 4 (delta)

ornithine transcarbamylase

biogenesis of lysosome-related organelles complex-1, subunit 2

eukaryotic translation initiation factor 3 , subunit 6

zinc finger protein 364

oxidase assembly 1 -like

BRCA2 and CDKN1A interacting protein

cadherin 2

zinc binding alcohol dehydrogenase, domain containing 1

fatty acid desaturase 1

zinc finger, A20 domain containing 3

melanocyte proliferating gene 1

ornithine decarboxylase antizyme inhibitor

proteasome (prosome, macropain) subunit, beta type 4

Kinesin family member $1 \mathrm{C}$

ribosomal protein S24

DALR anticodon binding domain containing 3

mannosidase, alpha, class $2 \mathrm{C}$, member 1

peroxisomal biogenesis factor 6

COP9 (constitutive photomorphogenic) homolog, subunit 6

integrin beta 4 binding protein

low density lipoprotein receptor-related protein associated protein 1

fibroblast growth factor inducible 14

catenin alpha 1

GPI anchor attachment protein

ras homolog gene family, member $\mathrm{Q}$

cytochrome c oxidase subunit VIla polypeptide 2-like

dystrobrevin binding protein 1

glutamate dehydrogenase 1

embryonic ectoderm development

BRCA1 associated protein

nudix (nucleoside diphosphate linked moiety $\mathrm{X}$ )-type motif 14

tripartite motif protein 28

\begin{tabular}{lll} 
Dnaja2 & 1.27 & 0.000 \\
Mrpl39 & 1.27 & 0.001 \\
Cryz & 1.27 & 0.008 \\
Cct4 & 1.26 & 0.003 \\
Otc & 1.26 & 0.005 \\
Bloc1s2 & 1.26 & 0.004 \\
Eif3s6 & 1.26 & 0.001 \\
Zfp364 & 1.25 & 0.004 \\
Oxa1l & 1.25 & 0.003 \\
Bccip & 1.25 & 0.005 \\
Cdh2 & 1.25 & 0.001 \\
Zadh1 & 1.24 & 0.006 \\
Fads1 & 1.24 & 0.003 \\
Za20d3 & 1.24 & 0.004 \\
MGI:1929864 & 1.24 & 0.003 \\
Oazin & 1.24 & 0.009 \\
Psmb4 & 1.24 & 0.000 \\
Kif1c & 1.24 & 0.005 \\
Rps24 & 1.24 & 0.009 \\
Dalrd3 & 1.24 & 0.000 \\
Man2c1 & 1.23 & 0.000 \\
Pex6 & 1.23 & 0.005 \\
Cops6 & 1.23 & 0.001 \\
Itgb4bp & 1.23 & 0.003 \\
Lrpap1 & 1.23 & 0.003 \\
Fin14 & 1.23 & 0.008 \\
Catna1 & 1.23 & 0.009 \\
Gpaa1 & 1.23 & 0.004 \\
Rhoq & 1.22 & 0.008 \\
Cox7a2l & 1.22 & 0.001 \\
Dtnbp1 & 1.22 & 0.006 \\
Glud1 & 1.22 & 0.005 \\
Eed & 1.22 & 0.000 \\
Brap & 1.21 & 0.004 \\
Nudt14 & 1.21 & 0.000 \\
Trim28 & 1.21 & 0.002 \\
& & \\
\hline
\end{tabular}


1416769_s_at 1416394 at 1438292_x_at 1456580_s_at 1428709_a_at 1417809 at 1424892_at

1430500_s_at

1417452_a_at

1421944_a_at

1428326 s at 1424461_at

1425381_a_at 1421842_a_at

1415761_at

1415678 at

1454638_a_at

1451149 at

1454763_at

1424540 at

1433934_at

1451328_at

1417909_at

1418988 at

1415863_at

1448336_at

1416605 at

1423911_at

1423702_at

1435967_s_at

1433850_at

1422693_a_at

1418897_at

1431766_x_at

1431177_a_at

1435862_at
ATPase, $\mathrm{H}+$ transporting, $\mathrm{V} 0$ subunit $\mathrm{B}$

Bcl2-associated athanogene 1

adenosine kinase

ATP synthase, $\mathrm{H}+$ transporting, mitochondrial F1 complex, delta subunit

mitochondrial ribosomal protein L24

solute carrier family 22 (organic cation transporter), member 18

zinc finger protein 95

metaxin 2

Finkel-Biskis-Reilly murine sarcoma virus ubiquitously expressed

asialoglycoprotein receptor 1

heat-responsive protein 12

dynactin 2

transferrin receptor 2

secretory carrier membrane protein 4

mitochondrial ribosomal protein L52

protein phosphatase $1 \mathrm{~A}$, magnesium dependent, alpha isoform

phenylalanine hydroxylase

phosphoglucomutase 2

ankyrin repeat domain 17

Homeodomain interacting protein kinase 1

SEC24 related gene family, member A (S. cerevisiae)

pecanex-like 3 (Drosophila)

serine (or cysteine) proteinase inhibitor, clade $C$ (antithrombin), member 1 peroxisome biogenesis factor 7

eukaryotic translation initiation factor 4 , gamma 2

developmentally regulated GTP binding protein 1

nucleolar protein family $\mathrm{A}$, member 2

protein phosphatase 2 , regulatory subunit $B$ (B56), alpha isoform

mistone family, member 0

3-hydroxyisobutyrate dehydrogenase

protein phosphatase 4 , regulatory subunit 2

RNA polymerase II transcriptional coactivator

coagulation factor II

ribosomal protein $\mathrm{S} 2$

ribosomal protein L10A

Son cell proliferation protein

\begin{tabular}{lll} 
Atp6v0b & 1.21 & 0.000 \\
Bag1 & 1.21 & 0.008 \\
Adk & 1.21 & 0.009 \\
Atp5d & 1.20 & 0.009 \\
Mrpl24 & 1.20 & 0.005 \\
Slc22a18 & 1.20 & 0.007 \\
Zfp95 & 1.20 & 0.006 \\
Mtx2 & 1.20 & 0.008 \\
Fau & 1.20 & 0.009 \\
Asgr1 & 1.20 & 0.002 \\
Hrsp12 & 1.20 & 0.003 \\
Dctn2 & 1.20 & 0.009 \\
Trfr2 & 1.19 & 0.000 \\
Scamp4 & 1.19 & 0.001 \\
Mrpl52 & 1.19 & 0.005 \\
Ppm1a & 1.18 & 0.005 \\
Pah & 1.17 & 0.001 \\
Pgm2 & 1.17 & 0.002 \\
Ankrd17 & 1.17 & 0.004 \\
Hipk1 & 1.16 & 0.002 \\
Sec24a & 1.16 & 0.005 \\
Pcnxl3 & 1.16 & 0.005 \\
Serpinc1 & 1.15 & 0.000 \\
Pex7 & 1.15 & 0.008 \\
Eif4g2 & 1.15 & 0.005 \\
Drg1 & 1.14 & 0.004 \\
Nola2 & 1.14 & 0.010 \\
Ppp2r5a & 1.13 & 0.005 \\
H1f0 & 1.11 & 0.004 \\
Hibadh & 1.11 & 0.002 \\
Ppp4r2 & 1.10 & 0.005 \\
Rpo2tc1 & 1.09 & 0.000 \\
F2 & 1.07 & 0.008 \\
Rps2 & -1.08 & 0.002 \\
Rpl10a & -1.11 & 0.001 \\
Son & -1.11 & 0.004 \\
& & \\
\hline
\end{tabular}


1416170_at 1416025 at 1434854_a_at 1434814_x_at 1460186_at 1428152_a_at 1416565_at

1419364_a_a

1452032

1426522_at

1428868 a at 1433569_x_at 1415876_a_at 1424368_s_at 1450845_a_a 1423993_at

1422819_at

1422525_at

1424721_at

1438000 x at

1423643_at

1418101_a_at

1439259_x_at

1418625_s_at

1418016_at

AFFX-GapdhMur/M similar to glyceraldehyde-3-phosphate dehydrogenase

1452220 at

1415713_a_at

1459832_s_at

1447778_x_at

1419984_s_at

1422613_a_at

1433648_at

1450187_a_at

1417847_at

1454778_x_at
TNF receptor-associated protein 1

fibrinogen, gamma polypeptide

ribosomal protein $\mathrm{S} 10$

glucose phosphate isomerase 1

SM-11044 binding protei

osomal protein L18A

cytochrome c oxidase, subunit VIb polypeptide 1

somal protein $\mathrm{S} 7$

protein kinase, CAMP dependent regulatory, type I, alpha

hydroxyacyl-CoA deh/ase/3-ketoacyl-CoA thiolase/enoyl-CoA hydratase

ornithine decarboxylase antizyme

RAN, member RAS oncogene family

ribosomal protein S26

\section{ubiquilin 1}

basic leucine zipper and W2 domains 1

ATPase, $\mathrm{H}+$ transporting, $\mathrm{V} 1$ subunit $\mathrm{F}$

mitochondrial ribosomal protein L36

ATP synthase, $\mathrm{H}+$ transporting, mitochondrial F1F0 complex, subunit

microfibrillar-associated protein 3

zinc finger protein 622

DEAD (Asp-Glu-Ala-Asp) box polypeptide 39

abhydrolase domain containing 4

similar to glyceraldehyde-3-phosphate dehydrogenase

DEAD (Asp-Glu-Ala-Asp) box polypeptide 24

adaptor-related protein complex AP-1, mu subunit 1

\section{c6.1a protein}

zinc finger protein 644

ribosomal protein $\mathrm{L} 7 \mathrm{a}$

sperm associated antigen 9

galactose-1-phosphate uridyl transferase

Unc-51 like kinase 2 (C. elegans)

Ribosomal protein $\mathrm{S} 28$

\begin{tabular}{lll} 
Trap1 & -1.12 & 0.006 \\
Fgg & -1.12 & 0.006 \\
Rps10 & -1.12 & 0.009 \\
Gpi1 & -1.13 & 0.007 \\
MGl:1914262 & -1.14 & 0.004 \\
Rpl18a & -1.14 & 0.002 \\
Cox6b1 & -1.14 & 0.001 \\
Rps7 & -1.14 & 0.008 \\
Prkar1a & -1.14 & 0.006 \\
Hadhb & -1.15 & 0.005 \\
Oaz1 & -1.15 & 0.010 \\
Ran & -1.15 & 0.002 \\
Rps26 & -1.16 & 0.001 \\
Ubqln1 & -1.16 & 0.008 \\
Bzw1 & -1.17 & 0.002 \\
Atp6v1f & -1.17 & 0.001 \\
Mrpl36 & -1.17 & 0.001 \\
Atp5k & -1.17 & 0.007 \\
Mfap3 & -1.18 & 0.004 \\
Zfp622 & -1.18 & 0.008 \\
Ddx39 & -1.18 & 0.005 \\
Rtn3 & -1.19 & 0.008 \\
Abhd4 & -1.19 & 0.009 \\
LOC14433 III LOI & -1.19 & 0.009 \\
Pum2 & -1.19 & 0.002 \\
LOC14433 I/I LOI & -1.19 & 0.006 \\
Dock1 & -1.19 & 0.009 \\
Ddx24 & -1.19 & 0.006 \\
Ap1m1 & -1.20 & 0.008 \\
MGI:2389572 & -1.20 & 0.009 \\
Zfp644 & -1.20 & 0.002 \\
Rpl7a & -1.20 & 0.003 \\
Spag9 & -1.21 & 0.006 \\
Galt & -1.21 & 0.008 \\
Ulk2 & -1.21 & 0.006 \\
Rps28 & -1.21 & 0.010 \\
\hline
\end{tabular}


1434251_at

1452196 a at 1452545_a_at 1451074_at 1431037_a_at 1460571_at

1437309_a_at

1420830_x_at

1436900_x_at

1418626_a_at

1455432_at

1423050_s_at

1435900_at

1450668_s_at

1434017 at

1423076_at

1425137_a_at

1434066 at

1435518_at

1418115 s at

1448198_a_at

1416386_a_at

1423599_a_at

1415980 at

1426688_at

1454979_at

1423972 at

1423754_at

1426976_at

1450186_s_at

1439156_at

1419399_at

1424639_a_at

1422848_a_at

1433541_a_at

1449930_a_at
CCR4-NOT transcription complex, subunit 1

NCK-associated protein 1

integrin beta 1 (fibronectin receptor beta)

ring finger protein 13

ELAV (embryonic lethal, abnormal vision, Drosophila)-like 1 (Hu antigen R)

Dicer1, Dcr-1 homolog (Drosophila)

replication protein $\mathrm{A} 1$

tyrosine 3-monooxygenase/tryptophan 5-monooxygenase activation protein

leptin receptor overlapping transcript

clusterin

TAO kinase 1

heterogeneous nuclear ribonucleoprotein $U$

zinc finger protein 297B

heat shock protein 1 (chaperonin 10)

zinc and ring finger 2

sorting nexin 9

histocompatibility 2, Q region locus 10

general transcription factor III C 1

RAS related protein $1 b$

interferon alpha responsive gene

NADH dehydrogenase (ubiquinone) 1 beta subcomplex 8

mannose-6-phosphate receptor, cation dependent

\section{phosducin-like}

ATP synthase, $\mathrm{H}+$ transporting, mitochondrial F0 complex, subunit $\mathrm{C}$

succinate dehydrogenase complex, subunit $A$, flavoprotein $(\mathrm{Fp}$ )

diaphanous homolog 1 (Drosophila)

electron transferring flavoprotein, alpha polypeptide

interferon induced transmembrane protein 3

ubiquitin specific protease 47

GNAS (guanine nucleotide binding protein, alpha stimulating) complex locus gene model 962, (NCBI)

microsomal triglyceride transfer protein

3-hydroxy-3-methylglutaryl-Coenzyme A lyase

poly(A) binding protein, nuclear 1

ubiquitin associated protein 2-like

signal sequence receptor, beta

$\begin{array}{lll}\text { Cnot1 } & -1.21 & 0.008 \\ \text { Nckap1 } & -1.21 & 0.009 \\ \text { Itgb1 } & -1.21 & 0.000 \\ \text { Rnf13 } & -1.21 & 0.010 \\ \text { Elavl1 } & -1.22 & 0.006 \\ \text { Dicer1 } & -1.22 & 0.008 \\ \text { Rpa1 } & -1.22 & 0.003 \\ \text { Ywhaq } & -1.22 & 0.007 \\ \text { Leprot } & -1.22 & 0.006 \\ \text { Clu } & -1.22 & 0.000 \\ \text { Taok1 } & -1.22 & 0.002 \\ \text { Hnrpu } & -1.23 & 0.002 \\ \text { Zfp297b } & -1.23 & 0.000 \\ \text { Hspe1 } & -1.24 & 0.003 \\ \text { Znrf2 } & -1.24 & 0.000 \\ \text { Snx9 } & -1.24 & 0.007 \\ \text { H2-Q10 } & -1.24 & 0.000 \\ \text { Gtf3c1 } & -1.24 & 0.009 \\ \text { Rap1b } & -1.24 & 0.006 \\ \text { MGl:1929890 } & -1.24 & 0.002 \\ \text { Ndufb8 } & -1.24 & 0.001 \\ \text { M6pr } & -1.24 & 0.010 \\ \text { Pdcl } & -1.24 & 0.003 \\ \text { Atp5g2 } & -1.24 & 0.002 \\ \text { Sdha } & -1.25 & 0.000 \\ \text { Diap1 } & -1.25 & 0.004 \\ \text { Etfa } & -1.25 & 0.003 \\ \text { Ifitm3 } & -1.25 & 0.001 \\ \text { Usp47 } & -1.25 & 0.002 \\ \text { Gnas } & -1.25 & 0.003 \\ \text { Gm962 } & -1.25 & 0.009 \\ \text { Mttp } & -1.25 & 0.007 \\ \text { Hmgcl } & -1.25 & 0.005 \\ \text { Pabpn1 } & -1.25 & 0.001 \\ \text { Ubap2l } & -1.26 & 0.001 \\ \text { Ssr2 } & -1.26 & 0.003 \\ & & \end{array}$


1448324_at 1416197_at 1448799_s_at 1450406_a_at 1426449_a_at 1454605 a at 1416409_at

1416347_at

1428608_at 1434851_s_at

1416335 1438606_a_at 1460341_at 1423075_at 1417227 at 1416984_at 1437474_at 1415672 at 1452038_at 1454847_at 1441075_at 1452820_at 1415882_at 1424280 at 1425803_a_at 1450818_a_at 1422103 a at 1427971_at 1434801_x_at 1422480_at

1456133_x_at 1451318_a_at 1416556_at 1434796 at 1437741_at 1416510_at ribonucleic acid binding protein S1

U1 small nuclear ribonucleoprotein 1C

mitochondrial ribosomal protein S12

ST3 beta-galactoside alpha-2,3-sialyltransferase 3

praja1, RING-H2 motif containing

phosphatidylinositol 4-kinase type 2 alpha

acyl-Coenzyme A oxidase 1, palmitoyl

multiple endocrine neoplasia 1

myosin light chain, regulatory $B$

crumbs homolog 3 (Drosophila)

macrophage migration inhibitory factor

chloride intracellular channel 4 (mitochondrial)

pleckstrin homology domain containing, family B (evectins) member 2

lectin, mannose-binding 2

methylcrotonoyl-Coenzyme A carboxylase 1 (alpha)

mitochondrial ribosomal protein S18A

GATA zinc finger domain containing $2 \mathrm{~B}$

golgi autoantigen, golgin subfamily $\mathrm{a}, 7$

capping protein (actin filament) muscle Z-line, alpha 1

lipoma HMGIC fusion partner-like 2

nitric oxide synthase trafficker

WD repeat domain 11

growth hormone inducible transmembrane protein

motile sperm domain containing 1

methyl-CpG binding domain protein 2

NADH dehydrogenase (ubiquinone) 1 alpha subcomplex, 7 (B14.5a)

signal transducer and activator of transcription $5 \mathrm{~B}$

hyperparathyroidism 2 homolog (human)

carrier family 25 member 5

sorting nexin 3

integrin beta 5

Yamaguchi sarcoma viral (v-yes-1) oncogene homolog

sarcoma amplified sequence

vesicle-associated membrane protein 4

RAB21, member RAS oncogene family

mitochondrial ribosomal protein $\mathrm{L} 4$

\begin{tabular}{lll} 
Rnps1 & -1.26 & 0.005 \\
Snrp1c & -1.26 & 0.008 \\
Mrps12 & -1.26 & 0.002 \\
St3gal3 & -1.26 & 0.001 \\
Pja1 & -1.26 & 0.006 \\
Pi4k2a & -1.26 & 0.007 \\
Acox1 & -1.26 & 0.003 \\
Men1 & -1.27 & 0.001 \\
Mylc2b & -1.27 & 0.005 \\
Crb3 & -1.27 & 0.007 \\
Mif & -1.27 & 0.007 \\
Clic4 & -1.27 & 0.005 \\
Plekhb2 & -1.27 & 0.005 \\
Lman2 & -1.28 & 0.005 \\
Mccc1 & -1.28 & 0.005 \\
Mrps18a & -1.28 & 0.009 \\
Gatad2b & -1.28 & 0.009 \\
Golga7 & -1.28 & 0.004 \\
Capza1 & -1.28 & 0.001 \\
Lhfpl2 & -1.28 & 0.005 \\
LOC329416 & -1.29 & 0.009 \\
Wdr11 & -1.29 & 0.001 \\
Ghitm & -1.29 & 0.002 \\
Mospd1 & -1.29 & 0.001 \\
Mbd2 & -1.29 & 0.001 \\
Ndufa7 & -1.30 & 0.005 \\
Stat5b & -1.30 & 0.002 \\
Hrpt2 & -1.30 & 0.002 \\
Slc25a5 & -1.30 & 0.001 \\
Snx3 & -1.30 & 0.009 \\
Itgb5 & -1.31 & 0.002 \\
Lyn & -1.31 & 0.002 \\
Sas & -1.31 & 0.006 \\
Vamp4 & -1.32 & 0.001 \\
Rab21 & -1.32 & 0.010 \\
Mrpl4 & -1.32 & 0.002 \\
\hline
\end{tabular}


1426238_at

1426554 a at

1437211_x_at

1454852_at

1433910_at

1446778_at

1421823_a_at

1416407_at

1454894_at

1426857_a_at

1434608 at

1455164_at

1438155_x_at

1440211_at

1446618 at

1418151_at

1446087_at

1423235 at

1424052_at

1427415 at

1423694_at

1423727_at

1416099_at

1423210_a_a

1433631_at

1429528_at

1428442 at

1421870_at

1416280_at

1450957_a_at

1451969_s_at

1417086_at

1423200_at

1423532_at

1421101_a_at

1443351_at bone morphogenetic protein 1

phosphoglycerate mutase 1

ELOVL family member 5 , elongation of long chain fatty acids (yeast)

trans-acting transcription factor 1

zinc finger, $\mathrm{CCHC}$ domain containing 6

Hormonally upregulated Neu-associated kinase

protein phosphatase $2 \mathrm{a}$, catalytic subunit, beta isoform

phosphoprotein enriched in astrocytes 15

SMAD specific E3 ubiquitin protein ligase 2

hydroxysteroid dehydrogenase like 2

DEAD (Asp-Glu-Ala-Asp) box polypeptide 52

Cdc42 GTPase-activating protein

phosphatidylinositol glycan, class $O$

cytochrome P450, family 2, subfamily j, polypeptide 11

hypothetical gene supported by AK038224

myotubularin related protein 4

Golgi autoantigen, golgin subfamily a, 1

adaptor-related protein complex 3 , beta 1 subunit

THAP domain containing 4

F-box protein 43

potassium channel tetramerisation domain containing 10

cornichon homolog (Drosophila)

ribosomal protein $\mathrm{L} 27$

nucleolar protein family $\mathrm{A}$, member 3

eukaryotic translation initiation factor 5

RAE1 RNA export 1 homolog (S. pombe)

matrix metalloproteinase 24

tripartite motif-containing 44

(sentrin) activating enzyme E1B

\section{sequestosome 1}

poly (ADP-ribose) polymerase family, member 3

platelet-activating factor acetylhydrolase, isoform $1 \mathrm{~b}$, beta1 subunit

nuclear receptor co-repressor 1

ring finger protein 44

LIM domain binding 2

Glycine receptor, alpha 2 subunit

$\begin{array}{lll}\text { Bmp1 } & -1.32 & 0.004 \\ \text { Pgam1 } & -1.32 & 0.001 \\ \text { Elovl5 } & -1.32 & 0.010 \\ \text { Sp1 } & -1.32 & 0.003 \\ \text { Zcchc6 } & -1.32 & 0.001 \\ \text { Hunk } & -1.32 & 0.002 \\ \text { Ppp2cb } & -1.32 & 0.001 \\ \text { Pea15 } & -1.32 & 0.007 \\ \text { Smurf2 } & -1.33 & 0.001 \\ \text { Hsdl2 } & -1.33 & 0.008 \\ \text { Ddx52 } & -1.33 & 0.008 \\ \text { Cdgap } & -1.33 & 0.004 \\ \text { Pigo } & -1.33 & 0.002 \\ \text { Cyp2j11 } & -1.34 & 0.002 \\ \text { LOC432971 } & -1.34 & 0.006 \\ \text { Mtmr4 } & -1.34 & 0.002 \\ \text { Golga1 } & -1.34 & 0.007 \\ \text { Ap3b1 } & -1.34 & 0.002 \\ \text { Thap4 } & -1.34 & 0.002 \\ \text { Fbxo43 } & -1.34 & 0.002 \\ \text { Kctd10 } & -1.34 & 0.002 \\ \text { Cnih } & -1.34 & 0.001 \\ \text { Rpl27 } & -1.34 & 0.003 \\ \text { Nola3 } & -1.34 & 0.005 \\ \text { Eif5 } & -1.35 & 0.003 \\ \text { Rae1 } & -1.35 & 0.000 \\ \text { Mmp24 } & -1.35 & 0.006 \\ \text { Trim44 } & -1.35 & 0.005 \\ \text { Uble1b } & -1.35 & 0.002 \\ \text { Sqstm1 } & -1.35 & 0.009 \\ \text { Parp3 } & -1.35 & 0.008 \\ \text { Pafah1b1 } & -1.36 & 0.004 \\ \text { Ncor1 } & -1.36 & 0.003 \\ \text { Rnf44 } & -1.36 & 0.005 \\ \text { Ldb2 } & -1.36 & 0.008 \\ \text { Glra2 } & -1.36 & 0.010\end{array}$


1448726_at

1437347_at

1417931_at

1434487_at

1421606_a_at

1415814_at

1427718_a_at

1448813_at

1449024_a_a

1455534_s_at

1416036 at

1419423_at

1453055_at

1452540_a_at

1415936 at

1433547_s_at

1426160_a_at

1435093 at

1417119_at

1448823 at

1419495_at

1415709_s_at

1437329_at

1448734 at

1433497_at

1417324_at

1451230_a_at

1424523_at

1458247_s_at

1452582_at

1454932_at

1419244_a_at

1424255_at

1448448_a_at

1451833_a_at

1448737_at small nuclear RNA activating complex, polypeptide 2

endothelin receptor type $B$

$\mathrm{N}$-deacetylase/ $\mathrm{N}$-sulfotransferase (heparan glucosaminyl) 2

myocyte enhancer factor $2 \mathrm{D}$

sulfotransferase family $4 \mathrm{~A}$, member 1

ATPase, $\mathrm{H}+$ transporting, $\mathrm{V} 1$ subunit $\mathrm{B}$, isoform 2

transformed mouse 3 Т 3 cell double minute 2

arylacetamide deacetylase (esterase)

hexosaminidase $A$

oxysterol binding protein-like 11

FK506 binding protein $1 \mathrm{a}$

stabilin 2

semaphorin $6 \mathrm{D}$

histone $1, \mathrm{H} 2 \mathrm{~b}$

breast cancer anti-estrogen resistance 3

NudC domain containing 1

serine/threonine kinase 16

zinc finger, FYVE domain containing 20

zinc finger like protein 1

chemokine (C-X-C motif) ligand 12

inner mitochondrial membrane peptidase 2-like (S. cerevisiae)

golgi-specific brefeldin A-resistance factor 1

Protein tyrosine phosphatase-like member $b$

ceruloplasmin

aquarius

microtubule associated serine/threonine kinase 2

WW domain binding protein 5

engulfment and cell motility 1 , ced-12 homolog (C. elegans)

dynactin 5

galactose mutarotase

REST corepressor 1

RAB14, member RAS oncogene family

suppressor of Ty 5 homolog (S. cerevisiae)

choline kinase beta

SET domain, bifurcated 1

tetraspanin 7

\begin{tabular}{lll} 
Snapc2 & -1.36 & 0.003 \\
Ednrb & -1.37 & 0.002 \\
Ndst2 & -1.37 & 0.001 \\
Mef2d & -1.37 & 0.009 \\
Sult4a1 & -1.37 & 0.007 \\
Atp6v1b2 & -1.37 & 0.004 \\
Mdm2 & -1.37 & 0.006 \\
Aadac & -1.37 & 0.004 \\
Hexa & -1.37 & 0.002 \\
Osbpl11 & -1.37 & 0.010 \\
Fkbp1a & -1.37 & 0.007 \\
Stab2 & -1.37 & 0.004 \\
Sema6d & -1.37 & 0.000 \\
Hist1h2bc II Hist: & -1.37 & 0.004 \\
Bcar3 & -1.38 & 0.002 \\
Nudcd1 & -1.38 & 0.008 \\
Stk16 & -1.38 & 0.002 \\
Zfyve20 & -1.38 & 0.005 \\
Zfpl1 & -1.38 & 0.002 \\
Cxcl12 & -1.38 & 0.000 \\
Immp2l & -1.38 & 0.001 \\
Gbf1 & -1.38 & 0.004 \\
Ptplb & -1.38 & 0.005 \\
Cp & -1.38 & 0.004 \\
Aqr & -1.38 & 0.004 \\
Mast2 & -1.39 & 0.005 \\
Wbp5 & -1.39 & 0.001 \\
Elmo1 & -1.39 & 0.005 \\
Dctn5 & -1.39 & 0.003 \\
Galm & -1.39 & 0.000 \\
Rcor1 & -1.39 & 0.003 \\
Rab14 & -1.39 & 0.004 \\
Supt5h & -1.39 & 0.000 \\
Chkb & -1.39 & 0.003 \\
Setdb1 & -1.39 & 0.007 \\
Tspan7 & -1.39 & 0.002 \\
\hline
\end{tabular}


1454916_s_at

ADP-ribosylation factor interacting protein 1

1459679_s_at myosin IB

1450011_at hydroxysteroid (17-beta) dehydrogenase 12

1417801 a at protein tyrosine phosphatase, receptor-type, $F$ interacting protein, bp 2

1429681_a_at

1450844 at

1438041_at

1433748_at

1420440_at

1422736_at

1456131_x_at

1448232_x_at

1415760_s_at

1428846_at

1447898_s_at

1415887_at

1448503_at

1416577_a_at

1452272_a_at

1460330_a

1423916_s_at

1425051 at

1436363_a_at

1418436_at

1416026_a_at

1441945_s_at

1429251_at

1448219_a_at

1449001 at

1422601_at

1422559_at

glycoprotein, synaptic 2

syntaxin 6

Phosphodiesterase 7A

zinc finger, $\mathrm{DHHC}$ domain containing 18

pancreatic polypeptide

RAN binding protein 9

dystroglycan 1

tubulin, alpha 6

ATX1 (antioxidant protein 1) homolog 1 (yeast)

tetratricopeptide repeat domain 14

splicing factor, arginine/serine-rich 6

Trk-fused gene

myeloid cell leukemia sequence 1

ring-box 1

growth factor, erv1

annexin A3

myeloid leukemia factor 2

isochorismatase domain containing 1

nuclear factor $\mathrm{I} / \mathrm{X}$

syntaxin 7

ribosomal protein L12

abhydrolase domain containing $14 \mathrm{~A}$

PR domain containing 2, with ZNF domain

tyrosine 3-monooxygenase

isovaleryl coenzyme A dehydrogenase

serine (or cysteine) proteinase inhibitor, clade B, member 9

ubiquitin-conjugating enzyme E2N

0.004

0.000

0.007

0.001

0.008

0.002

0.003

0.007

0.002

0.002

0.005

0.000

0.003

0.002

0.001

0.005

0.009

0.007

0.008

0.003

0.002

0.004

0.003

0.001

0.001

0.005

0.001

0.001

0.003

0.003

0.001

0.000

0.001

0.004

0.001 
1416366_at

1424057_at

1417291_at

1425891_a_at

1417902_at

1425458_a_at

1457664_x_at

1427546_at

1423743_at

1419053_at

1416086 at

1418502_a_at

1426994_at

1435235_at

1435972 at

1448812_at

1417566_at

1417271_a_at

1439201_at

1425464 at

1415674_a_at

1451244_a_at

1416968_a_at

1418510_s_at

1425850_a_a

1450980_at

1448709 at

1417826_at

1415971_at

1429352_at

1434329_s_at

1449027_at

1420631_a_at

1456125_a_at

1454268_a_at

1428756_at
NADH dehydrogenase (ubiquinone) 1, subcomplex unknown, 2

ganglioside-induced differentiation-associated-protein 2

tumor necrosis factor receptor superfamily, member 1a

regulated $\mathrm{TBC}$ protein 1

solute carrier family 19 (thiamine transporter), member 2

factor receptor bound protein 10

Complement component 2 (within $\mathrm{H}-2 \mathrm{~S}$ )

ATP-binding cassette, sub-family A ( $A B C 1)$, member $8 b$

archain 1

peroxisomal biogenesis factor 14

protein-tyrosine sulfotransferase 2

oxidation resistance 1

$\mathrm{PH}$ domain and leucine rich repeat protein phosphatase

thioredoxin-like 1

calpastatin

hippocalcin-like 1

abhydrolase domain containing 5

endoglin

ubiquitin specific protease 14

GATA binding protein 6

trafficking protein particle complex 4

zinc finger protein 422

hydroxy-delta-5-steroid dehydrogenase, 3 beta- and steroid delta-isomerase 7

F-box only protein 8

NIMA (never in mitosis gene a)-related expressed kinase 6

GTP binding protein 3

AT rich interactive domain $1 \mathrm{~A}$ (Swi1 like)

aldo-keto reductase family 1 , member E1

myristoylated alanine rich protein kinase $\mathrm{C}$ substrate

molybdenum cofactor sulfurase

adiponectin receptor 2

ras homolog gene family, member $U$

bladder cancer associated protein homolog (human)

dynein, cytoplasmic, light chain 1

cytochrome b-245, alpha polypeptide

aminoadipate-semialdehyde dehydrogenase-phosphopantetheinyl transferase

\begin{tabular}{lll} 
Ndufc2 & -1.43 & 0.001 \\
Gdap2 & -1.44 & 0.003 \\
Tnfrsf1a & -1.44 & 0.001 \\
Grtp1 & -1.44 & 0.009 \\
Slc19a2 & -1.44 & 0.004 \\
Grb10 & -1.44 & 0.008 \\
C2 & -1.44 & 0.006 \\
Abca8b & -1.44 & 0.008 \\
Arcn1 & -1.44 & 0.007 \\
Pex14 & -1.45 & 0.003 \\
Tpst2 & -1.45 & 0.001 \\
Oxr1 & -1.45 & 0.000 \\
Phlpp & -1.45 & 0.000 \\
Txn11 & -1.45 & 0.007 \\
Cast & -1.45 & 0.009 \\
Hpcal1 & -1.45 & 0.006 \\
Abhd5 & -1.45 & 0.004 \\
Eng & -1.45 & 0.002 \\
Usp14 & -1.46 & 0.009 \\
Gata6 & -1.46 & 0.008 \\
Trappc4 & -1.46 & 0.007 \\
Zfp422 & -1.46 & 0.002 \\
Hsd3b7 & -1.46 & 0.005 \\
Fbx08 & -1.46 & 0.000 \\
Nek6 & -1.46 & 0.001 \\
Gtpbp3 & -1.46 & 0.007 \\
Arid1a & -1.47 & 0.010 \\
Akr1e1 & -1.47 & 0.003 \\
Marcks & -1.47 & 0.003 \\
Mocos & -1.47 & 0.001 \\
Adipor2 & -1.47 & 0.002 \\
Rhou & -1.47 & 0.004 \\
Blcap & -1.48 & 0.008 \\
Dnclc1 & -1.48 & 0.002 \\
Cyba & -1.48 & 0.009 \\
Aasdhppt & -1.49 & 0.002 \\
\hline
\end{tabular}


1427260_a_at

1421217_a_a

1454823_at

1434717_at

1417783_at

1418648_at

1452262_at

1418084_at

1426055_a_at

1444713_at

1419614 at

1458684_at

1449464_at

1433992_at

1421846_at

1420673_a_at

1416250_at

1419022_a_at

1446624_at

1420617_at

1449455_at

1417580_s_at

1428785_at

1437325_x_a

1418863_at

1433439_at

1448629 at

1422001_at

1437277_x_at

1460025_at

1449137_at

1445348_at

1421210_at

1416960 at

1438264_a_at

1431146_a_at tropomyosin 3, gamma

lectin, galactose binding, soluble 9

WD repeat domain 37

Cullin 3

amyotrophic lateral sclerosis 2 (juvenile) homolog (human)

EGL nine homolog 3 (C. elegans)

GrpE-like 2, mitochondrial

neuropilin 1

phosphatidylinositol glycan, class $Q$

Ubiquitin specific protease 34

phospholipase A2, group XIIB

Synovial sarcoma translocation, Chromosome 18

potassium voltage-gated channel, subfamily Q, member 1

apical protein, Xenopus laevis-like

WD repeat and SOCS box-containing 2

acyl-Coenzyme $A$ oxidase 2 , branched chain

B-cell translocation gene 2, anti-proliferative

enolase 1, alpha non-neuron

Fukuyama type congenital muscular dystrophy homolog (human)

cytoplasmic polyadenylation element binding protein 4

hemopoietic cell kinase

nium binding protein 1

angiomotin-like 1

aldehyde dehydrogenase 18 family, member A1

GATA binding protein 4

copine I

Hermansky-Pudlak syndrome 4 homolog (human)

inhibin beta- $C$

ans lutaminase 2 , c polypeptide

leucine-rich repeats and immunoglobulin-like domains 2

pyruvate dehydrogenase E1 alpha 1

cell division cycle 40 homolog (yeast)

class II transactivator

beta-1,3-glucuronyltransferase 3 (glucuronosyltransferase I)

tripeptidyl peptidase II

copine VIII

\begin{tabular}{lll} 
Tpm3 & -1.49 & 0.003 \\
Lgals9 & -1.49 & 0.001 \\
Wdr37 & -1.49 & 0.009 \\
Cul3 & -1.49 & 0.004 \\
Als2 & -1.49 & 0.000 \\
Egln3 & -1.50 & 0.007 \\
Grpel2 & -1.50 & 0.006 \\
Nrp1 & -1.50 & 0.000 \\
Pigq & -1.50 & 0.002 \\
Usp34 & -1.50 & 0.010 \\
Pla2g12b & -1.50 & 0.002 \\
Ss18 & -1.51 & 0.004 \\
Kcnq1 & -1.51 & 0.001 \\
Apxl & -1.51 & 0.009 \\
Wsb2 & -1.51 & 0.002 \\
Acox2 & -1.52 & 0.001 \\
Btg2 & -1.52 & 0.009 \\
Eno1 & -1.52 & 0.000 \\
Fcmd & -1.52 & 0.001 \\
Cpeb4 & -1.53 & 0.001 \\
Hck & -1.53 & 0.002 \\
Selenbp1 & -1.53 & 0.003 \\
Amotl1 & -1.53 & 0.000 \\
Aldh18a1 & -1.53 & 0.008 \\
Gata4 & -1.53 & 0.001 \\
Cpne1 & -1.54 & 0.001 \\
Hps4 & -1.54 & 0.003 \\
Inhbc & -1.54 & 0.001 \\
Tgm2 & -1.55 & 0.008 \\
Lrig2 & -1.55 & 0.002 \\
Pdha1 & -1.55 & 0.001 \\
Cdc40 & -1.55 & 0.003 \\
C2ta & -1.55 & 0.005 \\
B3gat3 & -1.55 & 0.005 \\
Tpp2 & -1.55 & 0.002 \\
Cpne8 & -1.55 & 0.010 \\
\hline
\end{tabular}


1460606_at

1456727 a at

1452490_a_at

1419257_at

1418634_at

1449341_a_a

1420663_at

1436760_a_at

1426484

1427283_at

1455321 at

1423569_at

1452338_s_at

1422620_s_at

1441198_at

1451459_at

1455942_at

1433777 at

1453022_at

$1459973 \times$ at

1428644_at

1418825_at

1430570_at

1450792_at

1460232_s_at

1449068_at

1416329 at

1428615_at

1449574_a_at

1423278_at

1447209_at

1452154_at

1456098_a_at

1424344_s_at

1421884_at

1456341 a at hydroxysteroid (17-beta) dehydrogenase 13

casein kinase 1 , delta

adaptor protein complex AP-2, alpha 2 subunit

transcription elongation factor A (SII) 1

Notch gene homolog 1 (Drosophila)

T helper-inducing POZ/Krueppel factor

ribosomal protein $\mathrm{S} 8$

UBX domain containing 2

myeloid/lymphoid or mixed-lineage leukemia

DDD domain containing 1

glycine amidinotransferase (L-arginine:glycine amidinotransferase)

intersectin 1 (SH3 domain protein $1 \mathrm{~A})$

phosphatidic acid phosphatase $2 a$

zinc finger protein 39

embryonic large molecule derived from yolk sac

F-box and leucine-rich repeat protein 11

I(3)mbt-like 2 (Drosophila)

GPI-anchored HDL-binding protein 1

dipeptidylpeptidase 4

mannoside acetylglucosaminyltransferase 5

interferon inducible protein 1

kynureninase (L-kynurenine hydrolase)

TYRO protein tyrosine kinase binding protein

hydroxysteroid dehydrogenase-2, delta<5>-3-beta

zinc finger protein 148

cytoplasmic FMR1 interacting protein 1

purinergic receptor (family A group 5)

cell division cycle 42 homolog (S. cerevisiae)

protein tyrosine phosphatase, receptor type, $\mathrm{K}$

Forkhead box P1

isoleucine-tRNA synthetase

engulfment and cell motility 2 , ced-12 homolog (C. elegans)

eukaryotic translation initiation factor $1 \mathrm{~A}$

Son of sevenless homolog 1 (Drosophila)

basic transcription element binding protein 1

\begin{tabular}{lll} 
Hsd17b13 & -1.55 & 0.002 \\
Csnk1d & -1.56 & 0.000 \\
Ap2a2 & -1.56 & 0.004 \\
Tcea1 & -1.56 & 0.001 \\
Notch1 & -1.56 & 0.002 \\
Stom & -1.56 & 0.007 \\
Thpok & -1.56 & 0.009 \\
Rps8 & -1.56 & 0.004 \\
Ubxd2 & -1.56 & 0.005 \\
Mll & -1.56 & 0.004 \\
Ddhd1 & -1.57 & 0.001 \\
Gatm & -1.57 & 0.003 \\
Itsn1 & -1.57 & 0.001 \\
Ppap2a & -1.57 & 0.000 \\
Zfp39 & -1.57 & 0.001 \\
MGl:1915033 & -1.57 & 0.000 \\
Fbxl11 & -1.58 & 0.001 \\
L3mbt12 & -1.58 & 0.001 \\
MGl:1915703 & -1.58 & 0.002 \\
Dpp4 & -1.58 & 0.001 \\
Mgat5 & -1.58 & 0.005 \\
Ifi1 & -1.58 & 0.009 \\
Kynu & -1.58 & 0.010 \\
Tyrobp & -1.58 & 0.008 \\
Hsd3b2 III Hsd3b & -1.58 & 0.006 \\
Zfp148 & -1.58 & 0.001 \\
Cyfip1 & -1.59 & 0.001 \\
P2y5 & -1.59 & 0.002 \\
Cdc42 & -1.59 & 0.004 \\
Ptprk & -1.59 & 0.003 \\
Foxp1 & -1.60 & 0.004 \\
lars & -1.60 & 0.004 \\
Elmo2 & -1.60 & 0.004 \\
Eif1a & -1.60 & 0.010 \\
Sos1 & -1.60 & 0.001 \\
Bteb1 & -1.60 & 0.001 \\
\hline & & \\
\hline
\end{tabular}


1420558_at

1418547_at

1432072_at

1422703_at

1436755_at

1454654_at

1460700_at

1460326_at

1440134_at

1439167_at

1433723 s a

1449460_at

1457641_at

1424034_at

1419407_at

1428087_at

1420747_at

1418019 at

1452960_at

1448076_at

1433857_at

1452915_at

1419911_at

1422485_at

1420361_at

1427413_a_at

$1441870 \mathrm{~s}$ at

1449086_at

1430869_a_at

1452860_at

1456121_at

1457296_at

1449183_at

1438443 at

1419122_at

1450860_at selectin, platelet

tissue factor pathway inhibitor 2

kinesin family member $2 A$

glycerol kinase

inter-alpha (globulin) inhibitor $\mathrm{H} 5$

disrupted in renal carcinoma 2 (human)

signal transducer and activator of transcription 3

phosphatidylinositol 3-kinase, catalytic, alpha polypeptide

cytochrome P450, family 4, subfamily a, polypeptide 10

peroxisomal trans-2-enoyl-CoA reductase

Small EDRK-rich factor 2

ankyrin repeat and SOCS box-containing protein 13

CREB binding protein

RAR-related orphan receptor alpha

hemolytic complement

dynamin 1-like

per-pentamer repeat gene

carboxypeptidase $D$

SCY1-like 3 (S. cerevisiae)

(tetratricopeptide repeat containing)

fat tumor suppressor homolog (Drosophila)

protein kinase, cAMP dependent regulatory, type II alpha

Coronin, actin binding protein $1 C$

MAD homolog 4 (Drosophila)

solute carrier family 11 member 1

CUG triplet repeat, RNA binding protein 1

polycystic kidney disease 2

ring finger protein 141

hyaluronic acid binding protein 4

F-box and leucine-rich repeat protein 17

leucine-rich repeats and IQ motif containing 2

cartilage intermediate layer protein, nucleotide pyrophosphohydrolase

catechol-O-methyltransferase

zinc finger and BTB domain containing 20

methyltransferase-like 1

leucine aminopeptidase 3

\begin{tabular}{lll} 
Selp & -1.61 & 0.006 \\
Tfpi2 & -1.61 & 0.000 \\
Kif2a & -1.61 & 0.005 \\
Gyk & -1.61 & 0.003 \\
Itih5 & -1.61 & 0.002 \\
Dirc2 & -1.61 & 0.006 \\
Stat3 & -1.61 & 0.010 \\
Pik3ca & -1.61 & 0.000 \\
Cyp4a10 III BC01 & -1.61 & 0.007 \\
Pecr & -1.61 & 0.004 \\
Serf2 & -1.61 & 0.002 \\
Asb13 & -1.62 & 0.001 \\
Crebbp & -1.62 & 0.007 \\
Rora & -1.62 & 0.007 \\
Hc & -1.62 & 0.000 \\
Dnm11 & -1.63 & 0.000 \\
MGl:1349458 & -1.63 & 0.002 \\
Cpd & -1.63 & 0.001 \\
Scyl3 & -1.63 & 0.009 \\
Sh2bp1 & -1.63 & 0.004 \\
Fath & -1.63 & 0.009 \\
Prkar2a & -1.63 & 0.003 \\
Coro1c & -1.63 & 0.008 \\
Smad4 & -1.63 & 0.010 \\
Slc11a1 & -1.63 & 0.008 \\
Cugbp1 & -1.63 & 0.000 \\
Pkd2 & -1.63 & 0.000 \\
Rnf141 & -1.63 & 0.003 \\
Habp4 & -1.64 & 0.009 \\
Fbxl17 & -1.64 & 0.002 \\
Lrriq2 & -1.64 & 0.007 \\
Cilp & -1.64 & 0.005 \\
Comt & -1.64 & 0.003 \\
Zbtb20 & -1.64 & 0.006 \\
Mett11 & -1.65 & 0.007 \\
Lap3 & -1.65 & 0.001 \\
\hline & & \\
\hline
\end{tabular}


1448431_at 1423215_at 1419279_at 1455849_at 1417426_at 1425188_s_at 1428729_at

1436059_at

1415952_at 1453949_s_at

1434939 at 1419552_at 1420897_at 1417713_at 1450725_s_at 1433592 at

1422578_at 1450843_a_at 1424178_at

1422293 a at 1417244_a_at 1436739 at 1455567_at

1416412 at 1435751 at 1423462_at 1451131 at 1452740_at 1454930_at 1419061_at 1417231_at 1431105_a_at 1420920_a_at 1415874 at

1422661_at 1439153_at ankyrin repeat and SOCS box-containing protein 6 signal peptidase complex subunit 2 homolog (S. cerevisiae)

phosphatidylinositol-4-phosphate 5-kinase, type II, alpha

neuron navigator 1

proteoglycan 1 , secretory granule

(C. elegans)

cerebral cavernous malformations 1

regulatory factor X, 1 (influences HLA class II expression)

$\mathrm{MAP} /$ microtubule affinity-regulating kinase 2

lysophospholipase 1

forkhead box F1a

enoyl Coenzyme A hydratase domain containing 1

synaptosomal-associated protein 23

eukaryotic translation initiation factor 2 , subunit 2 (beta)

carbonic anhydrase 14

calmodulin 1

citrate synthase

serine (or cysteine) proteinase inhibitor, clade $\mathrm{H}$, member 1

transmembrane protein 38 a

potassium channel tetramerisation domain containing 1

interferon regulatory factor 7

angiotensin receptor 1

CDC2-related kinase 7

neutral sphingomyelinase ( $\mathrm{N}$-SMase) activation associated factor

ATP-binding cassette, sub-family C (CFTR/MRP), member 9

mitogen-activated protein kinase kinase kinase 7 interacting protein 2

ADP-ribosylation factor-like 6 interacting protein 1

myosin, heavy polypeptide 10 , non-muscle

cine rich repeat containing 35

ras homolog gene family, member $D$

claudin 2

transmembrane protein 33

ADP-ribosylation factor 1

sprouty homolog 1 (Drosophila)

lectin, galactose binding, soluble 8

IBR domain containing 2

\begin{tabular}{lll} 
Asb6 & -1.65 & 0.007 \\
Spcs2 & -1.65 & 0.008 \\
Pip5k2a & -1.65 & 0.003 \\
Nav1 & -1.65 & 0.008 \\
Prg1 & -1.65 & 0.000 \\
Sel1h & -1.65 & 0.007 \\
Ccm1 & -1.66 & 0.003 \\
Rfx1 & -1.66 & 0.007 \\
Mark2 & -1.66 & 0.001 \\
Lypla1 & -1.66 & 0.007 \\
Foxf1a & -1.66 & 0.007 \\
Echdc1 & -1.66 & 0.000 \\
Snap23 & -1.66 & 0.000 \\
Eif2s2 & -1.67 & 0.003 \\
Car14 & -1.67 & 0.006 \\
Calm1 & -1.67 & 0.000 \\
Cs & -1.67 & 0.000 \\
Serpinh1 & -1.67 & 0.006 \\
Tmem38a & -1.67 & 0.005 \\
Kctd1 & -1.68 & 0.009 \\
Irf7 & -1.68 & 0.005 \\
Agtr1 & -1.68 & 0.009 \\
Crk7 & -1.68 & 0.004 \\
Nsmaf & -1.68 & 0.004 \\
Abcc9 & -1.69 & 0.007 \\
Map3k7ip2 & -1.69 & 0.001 \\
Arl6ip1 & -1.69 & 0.007 \\
Myh10 & -1.70 & 0.005 \\
Lrrc35 & -1.70 & 0.000 \\
Rhod & -1.70 & 0.002 \\
Cldn2 & -1.70 & 0.001 \\
Tmem33 & -1.71 & 0.004 \\
Arf1 & -1.71 & 0.003 \\
Spry1 & -1.71 & 0.000 \\
Lgals8 & -1.71 & 0.004 \\
Ibrdc2 & -1.71 & 0.003 \\
\hline & & \\
\hline
\end{tabular}


1423006_at

1448318_at

1448493_at

1426529_a_at

1447187_at

1435136_at

1416256_a_a

1438320_s_at

1416762 a

1449107_at

1429183 at

1436868_at

1449164_at

1445374_at

1451231_a_at

1441981_at

1417673_at

1449970_at

1448304_a_at

1426441 at

1428631_a_at

1446302 at

1460316_at

1446571 at

1419913_at

1421720_a_at

1452091 a at

1455967_at

1416494_at

1416275_at

1437629_at

1438787_at

1455438_at

1415853 at

1416462_at

1436380_at proviral integration site 1

adipose differentiation related protein

polyadenylate-binding protein-interacting protein 2

ansgelin 2

Receptor interacting protein kinase 5

Wolf-Hirschhorn syndrome candidate 1 (human)

tubulin, beta 5

minichromosome maintenance deficient 7 (S. cerevisiae)

S100 calcium binding protein A10 (calpactin)

nudix (nucleoside diphosphate linked moiety $\mathrm{X}$ )-type motif 4

plakophilin 2

reticulon 4 receptor-like

668 antigen

Vesicle transport through interaction with t-SNAREs homolog $1 \mathrm{~A}$ (yeast)

cullin 2

transmembrane protease, serine $11 \mathrm{f}$

growth factor receptor bound protein 14

calpain 12

RAB6, member RAS oncogene family

solute carrier family 11 member 2

ubiquinol cytochrome c reductase core protein 2

Cysteine conjugate-beta lyase 1

Acyl-CoA synthetase long-chain family member 1

Mblk1-related protein-1

Serine/threonine kinase receptor associated protein

deltex 2 homolog (Drosophila)

RNA binding motif protein 28

Sorbin and SH3 domain containing 1

NADH dehydrogenase (ubiquinone) Fe-S protein 5

solute carrier family 26 , member 6

Rho guanine nucleotide exchange factor (GEF) 19

zinc finger protein 206

Peroxisomal membrane protein 4

differentially expressed in FDCP 8

GPI-anchored membrane protein 1

Cdc42 binding protein kinase alpha

$\begin{array}{lll}\text { Pim1 } & -1.71 & 0.004 \\ \text { Adfp } & -1.72 & 0.004 \\ \text { Paip2 } & -1.72 & 0.000 \\ \text { Tagln2 } & -1.72 & 0.009 \\ \text { Ripk5 } & -1.72 & 0.007 \\ \text { Whsc1 } & -1.73 & 0.008 \\ \text { Tubb5 } & -1.73 & 0.003 \\ \text { Mcm7 } & -1.74 & 0.000 \\ \text { S100a10 } & -1.74 & 0.009 \\ \text { Nudt4 } & -1.74 & 0.000 \\ \text { Pkp2 } & -1.74 & 0.000 \\ \text { Rtn4rl1 } & -1.74 & 0.005 \\ \text { Cd68 } & -1.75 & 0.000 \\ \text { Vti1a } & -1.75 & 0.007 \\ \text { Cul2 } & -1.75 & 0.001 \\ \text { Tmprss11f } & -1.75 & 0.006 \\ \text { Grb14 } & -1.75 & 0.000 \\ \text { Capn12 } & -1.76 & 0.007 \\ \text { Rab6 } & -1.76 & 0.001 \\ \text { Slc11a2 } & -1.76 & 0.006 \\ \text { Uqcrc2 } & -1.76 & 0.000 \\ \text { Ccbl1 } & -1.76 & 0.007 \\ \text { Acsl1 } & -1.77 & 0.000 \\ \text { Mlr1 } & -1.77 & 0.001 \\ \text { Strap } & -1.77 & 0.001 \\ \text { Dtx2 } & -1.77 & 0.009 \\ \text { Rbm28 } & -1.78 & 0.003 \\ \text { Sorbs1 } & -1.78 & 0.008 \\ \text { Ndufs5 } & -1.78 & 0.002 \\ \text { Slc26a6 } & -1.78 & 0.010 \\ \text { Arhgef19 } & -1.78 & 0.002 \\ \text { Zfp206 } & -1.79 & 0.006 \\ \text { Pxmp4 } & -1.79 & 0.004 \\ \text { Def8 } & -1.79 & 0.001 \\ \text { Gpiap1 } & -1.79 & 0.001 \\ \text { Cdc42bpa } & -1.79 & 0.000\end{array}$




\begin{tabular}{|c|c|c|c|c|}
\hline 1436753_at & aarF domain containing kinase 5 & Adck5 & -1.79 & 0.002 \\
\hline 1448529_at & thrombomodulin & Thbd & -1.79 & 0.004 \\
\hline 1436023_at & $\mathrm{BCL} 2$-associated transcription factor 1 & Bclaf1 & -1.80 & 0.007 \\
\hline 1455771_at & benzodiazapine receptor associated protein 1 & Bzrap1 & -1.80 & 0.006 \\
\hline 1423760_at & CD44 antigen & $\mathrm{Cd} 44$ & -1.80 & 0.002 \\
\hline 1422041_at & paired immunoglobin-like type 2 receptor beta & Pilrb & -1.81 & 0.009 \\
\hline 1418655_at & UDP-N-acetyl-alpha-D-galactosamine & Galgt1 & -1.81 & 0.000 \\
\hline 1457793_a_at & Wolf-Hirschhorn syndrome candidate 1-like 1 (human) & Whsc1l1 & -1.81 & 0.004 \\
\hline 1418949_at & growth differentiation factor 15 & Gdf15 & -1.81 & 0.006 \\
\hline 1427020_at & scavenger receptor class $\mathrm{A}$, member 3 & Scara3 & -1.82 & 0.007 \\
\hline 1433883_at & tropomyosin 4 & Tpm4 & -1.82 & 0.000 \\
\hline 1420096_at & Zinc finger proliferation 1 & Zipro1 & -1.83 & 0.003 \\
\hline 1416838_at & methylmalonyl-Coenzyme A mutase & Mut & -1.83 & 0.000 \\
\hline 1460351_at & S100 calcium binding protein A11 (calizzarin) & S100a11 & -1.83 & 0.002 \\
\hline 1450222_x_at & nerve growth factor, alpha & Ngfa & -1.83 & 0.004 \\
\hline 1445456_at & Potassium channel modulatory factor 1 & Kcmf1 & -1.83 & 0.000 \\
\hline 1450061_at & ectodermal-neural cortex 1 & Enc1 & -1.83 & 0.007 \\
\hline 1417624_at & Ngfi-A binding protein 1 & Nab1 & -1.83 & 0.001 \\
\hline 1429779_at & eukaryotic translation initiation factor $2 \mathrm{C}, 4$ & Eif2c4 & -1.83 & 0.001 \\
\hline 1449734_s_at & Bardet-Biedl syndrome 4 homolog (human) & Bbs4 & -1.83 & 0.001 \\
\hline 1419300_at & FMS-like tyrosine kinase 1 & Flt1 & -1.83 & 0.003 \\
\hline 1429187_at & transmembrane emp24 protein transport domain containing 7 & Tmed7 & -1.83 & 0.004 \\
\hline 1422909_at & SMC6 structural maintenance of chromosomes 6 -like 1 (yeast) & Smc6l1 & -1.84 & 0.004 \\
\hline 1438390_s_at & pituitary tumor-transforming 1 & Pttg1 & -1.84 & 0.000 \\
\hline 1450966_at & carnitine O-octanoyltransferase & Crot & -1.84 & 0.000 \\
\hline 1424140_at & galactose-4-epimerase, UDP & Gale & -1.85 & 0.006 \\
\hline 1460653_at & spinocerebellar ataxia 2 homolog (human) & Sca2 & -1.85 & 0.007 \\
\hline 1426556_at & suppressor of hairy wing homolog 4 (Drosophila) & Suhw4 & -1.86 & 0.003 \\
\hline 1437812_x_at & alpha glucosidase 2 alpha neutral subunit & Ganab & -1.86 & 0.001 \\
\hline 1436994_a_at & histone $1, \mathrm{H} 1 \mathrm{c}$ & Hist1h1c & -1.86 & 0.002 \\
\hline 1434834_at & suppressor of cytokine signaling 7 & Socs7 & -1.87 & 0.001 \\
\hline 1456042_s_at & T-complex expressed gene 4 & Tce4 & -1.87 & 0.003 \\
\hline 1448617_at & CD53 antigen & Cd53 & -1.87 & 0.007 \\
\hline 1419931_at & ATP-binding cassette, sub-family B (MDR/TAP), member 7 & Abcb7 & -1.87 & 0.000 \\
\hline 1439123_at & PHD finger protein $21 \mathrm{~A}$ & Bhc80 & -1.88 & 0.001 \\
\hline 1450783_at & interferon-induced protein with tetratricopeptide repeats 1 & Ifit1 & -1.88 & 0.009 \\
\hline
\end{tabular}


1417266_at

1416194_at

1419436_at

1416049_at

1417203_at

1418754_at

1438370_x_at

1416411_at

1423140_at

1435155_at

1419179 at

1436827_at

1420117_at

1437161_x_at

1418301_at

1456667_at

1455001_x_at

1425619_s_at

1449105_at

1417891 at

1437295_at

1449954_at

1428509_at

1443421_s_at

1420615_at

1451899_a_a

1438699 at

1451749_at

1433053_at

1419044_at

1419406_a_a

1449888 at

1424855_at

1420924 at

1418243_at

1449934_at chemokine (C-C motif) ligand 6

cytochrome P450, family 4, subfamily b, polypeptide 1

complement component factor h-like 1

glycine decarboxylase

ethylmalonic encephalopathy 1

adenylate cyclase 8

downstream of Stk11

glutathione S-transferase, mu 2

lysosomal acid lipase 1

cingulin

thioredoxin-like 4

gene model 944, (NCBI)

Golgi phosphoprotein 3

RNA binding protein gene with multiple splicing

interferon regulatory factor 6

Huntington disease gene homolog

Ribosomal protein L13a

desmoglein 2

$\mathrm{SH} 2$ domain protein $2 \mathrm{~A}$

(-complex expressed gene 1

protein kinase $\mathrm{N} 2$

hyaluronidase 1 /// $\mathrm{N}$-acetyltransferase 6

myosin IE

protocadherin beta 15

ash2 (absent, small, or homeotic)-like (Drosophila)

general transcription factor II I repeat domain-containing 1

Steroid 5 alpha-reductase 1

interleukin-1 receptor-associated kinase 4

egrin beta 2-like

contactin associated protein 4

(zinc finger protein)

endothelial PAS domain protein 1

thioesterase domain containing 1

tissue inhibitor of metalloproteinase 2

ficolin A

purine rich element binding protein $A$

$\begin{array}{lll}\text { Ccl6 } & -1.88 & 0.010 \\ \text { Cyp4b1 } & -1.89 & 0.002 \\ \text { Cfhl1 } & -1.89 & 0.000 \\ \text { Gldc } & -1.89 & 0.000 \\ \text { Ethe1 } & -1.90 & 0.001 \\ \text { Adcy8 } & -1.90 & 0.007 \\ \text { Dos } & -1.90 & 0.008 \\ \text { Gstm2 } & -1.90 & 0.000 \\ \text { Lip1 } & -1.90 & 0.001 \\ \text { Cgn } & -1.90 & 0.006 \\ \text { Txn14 } & -1.90 & 0.006 \\ \text { Gm944 } & -1.90 & 0.006 \\ \text { Golph3 } & -1.90 & 0.001 \\ \text { Rbpms } & -1.91 & 0.004 \\ \text { Irf6 } & -1.91 & 0.001 \\ \text { Hdh } & -1.91 & 0.001 \\ \text { Rpl13a } & -1.92 & 0.000 \\ \text { Dsg2 } & -1.93 & 0.009 \\ \text { Sh2d2a } & -1.93 & 0.004 \\ \text { Tce1 } & -1.93 & 0.003 \\ \text { Pkn2 } & -1.93 & 0.004 \\ \text { Hyal1 III Nat6 } & -1.94 & 0.003 \\ \text { Myo1e } & -1.95 & 0.000 \\ \text { Pcdhb15 } & -1.95 & 0.006 \\ \text { Ash2l } & -1.95 & 0.002 \\ \text { Gtf2ird1 } & -1.95 & 0.000 \\ \text { Srd5a1 } & -1.96 & 0.003 \\ \text { Irak4 } & -1.96 & 0.001 \\ \text { Itgb2l } & -1.96 & 0.005 \\ \text { Cntnap4 } & -1.98 & 0.004 \\ \text { Bcl11a } & -1.99 & 0.006 \\ \text { Epas1 } & -1.99 & 0.000 \\ \text { Thedc1 } & -1.99 & 0.007 \\ \text { Timp2 } & -1.99 & 0.000 \\ \text { Fcna } & -1.99 & 0.000 \\ \text { Pura } & -2.00 & 0.001 \\ \text { Mra } & & \end{array}$


1422411_s_at eosinophil-associated, ribonuclease A family, member 1

Kinesin family member $1 \mathrm{~B}$

1458426_at

PEST-containing nuclear protein

1452735_at

1428660_s_at torsin family 3, member A

1458410_at

1451847_s_at

GTPase activating RANGAP domain-like 1

1452045_at

1451018_at

1416321_s_at

1450857_a_a

1439638_at

1460592_at

1444913_at

1452324_at

1416530_a_at

1443029_at

1421028_a_a

1458566_at

1436764_at

1452391_at

1425567_a_at

1419449_a_at

1450004_at

1451139_at

1458850_at

1435647_at

1450984_at

1447411_at

1441677_at

1417612_at

1449846_at

1460225_at

1434314_s_at

1418456_a_at

1460348_at

4B (Rbp1 like)

zinc finger protein 281

leptin receptor overlapping transcript-like 1

proline arginine-rich end leucine-rich repeat

procollagen, type I, alpha 2

Erbb2 interacting protein

erythrocyte protein band 4.1-like 1

Hedgehog acyltransferase

plasmacytoma variant translocation 1

purine-nucleoside phosphorylase

PTPRF interacting protein, binding protein 1 (liprin beta 1 )

myocyte enhancer factor $2 \mathrm{C}$

$G$ patch domain containing 2

par-3 (partitioning defective 3 ) homolog (C. elegans)

coxsackievirus and adenovirus receptor

annexin A5

guanine nucleotide binding protein, alpha inhibiting 2

thymic stromal lymphopoietin

solute carrier family 39 (zinc transporter), member 4

Myosin, heavy polypeptide 7, cardiac muscle, beta

inhibitor of kappaB kinase gamma

tight junction protein 2

UDP-glucose dehydrogenase

SMC4 structural maintenance of chromosomes 4-like 1 (yeast)

immediate early response 5

eosinophil-associated, ribonuclease A family, member 2

mitochondrial ribosomal protein 63

RAB11 family interacting protein 5 (class I)

chemokine (C-X-C motif) ligand 14

MAD2 mitotic arrest deficient-like 2 (yeast)

F-box only protein $6 b$

\begin{tabular}{lll} 
Ear1 I// Ear2 III E & -2.00 & 0.007 \\
Kif1b & -2.00 & 0.003 \\
Pcnp & -2.00 & 0.001 \\
Tor3a & -2.00 & 0.002 \\
Garnl1 & -2.01 & 0.004 \\
Arid4b & -2.01 & 0.006 \\
Zfp281 & -2.02 & 0.004 \\
Leprotl1 & -2.02 & 0.004 \\
Prelp & -2.02 & 0.001 \\
Col1a2 & -2.02 & 0.007 \\
Erbb2ip & -2.03 & 0.005 \\
Epb4.1l1 & -2.04 & 0.003 \\
Hhat & -2.04 & 0.008 \\
Pvt1 & -2.04 & 0.003 \\
Pnp & -2.05 & 0.001 \\
Ppfibp1 & -2.05 & 0.004 \\
Mef2c & -2.05 & 0.007 \\
Gpatc2 & -2.05 & 0.001 \\
Pard3 & -2.06 & 0.006 \\
Cxadr & -2.06 & 0.008 \\
Anxa5 & -2.07 & 0.001 \\
Gnai2 & -2.07 & 0.000 \\
Tslp & -2.07 & 0.008 \\
Slc39a4 & -2.08 & 0.002 \\
Myh7 & -2.08 & 0.009 \\
Ikbkg & -2.08 & 0.000 \\
Tjp2 & -2.09 & 0.003 \\
Ugdh & -2.09 & 0.008 \\
Smc4l1 & -2.09 & 0.004 \\
ler5 & -2.09 & 0.002 \\
Ear2 & -2.11 & 0.005 \\
Mrp63 & -2.11 & 0.003 \\
Rab11fip5 & -2.11 & 0.009 \\
Cxcl14 & -2.13 & 0.003 \\
Mad2I2 & -2.13 & 0.001 \\
Fbxo6b & -2.15 & 0.004 \\
\hline
\end{tabular}

Fbxo6b

0.004 


\begin{tabular}{|c|c|c|c|c|}
\hline 1417023_a_at & fatty acid binding protein 4 , adipocyte & Fabp4 & -2.15 & 0.000 \\
\hline 1418659_at & circadian locomoter output cycles kaput & Clock & -2.15 & 0.005 \\
\hline 1460323_at & threonyl-tRNA synthetase & Tars & -2.15 & 0.003 \\
\hline 1416199_at & kinesin family member C3 & Kifc3 & -2.16 & 0.006 \\
\hline 1417292_at & interferon gamma inducible protein 47 & Ifi47 & -2.16 & 0.009 \\
\hline 1450156_a_at & hyaluronan mediated motility receptor (RHAMM) & $\mathrm{Hmmr}$ & -2.16 & 0.009 \\
\hline 1430802_at & histocompatibility 2, Q region locus 8 & $\mathrm{H} 2-\mathrm{Q} 8$ & -2.16 & 0.000 \\
\hline 1419483_at & complement component 3a receptor 1 & C3ar1 & -2.17 & 0.004 \\
\hline 1452381_at & cAMP responsive element binding protein 3 -like 2 & Creb312 & -2.17 & 0.008 \\
\hline 1431240_at & C-type lectin domain family 2 , member $\mathrm{h}$ & Clec2h & -2.17 & 0.009 \\
\hline 1449379_at & kinase insert domain protein receptor & $\mathrm{Kdr}$ & -2.17 & 0.004 \\
\hline 1452907_at & galactosylceramidase & Galc & -2.18 & 0.010 \\
\hline 1418090_at & plasmalemma vesicle associated protein & Plvap & -2.18 & 0.006 \\
\hline 1438421_at & poliovirus receptor-related 1 & Pvrl1 & -2.18 & 0.007 \\
\hline 1417689_a_at & PDZK1 interacting protein 1 & Pdzk1ip1 & -2.20 & 0.004 \\
\hline 1429653_at & genetic suppressor element 1 & Gse1 & -2.20 & 0.009 \\
\hline 1426140_x_at & killer cell lectin-like receptor, subfamily A, member 19 & Klra19 & -2.21 & 0.009 \\
\hline 1427201_at & musculoskeletal, embryonic nuclear protein 1 & Mustn1 & -2.21 & 0.001 \\
\hline 1440141_at & potassium voltage-gated channel, subfamily Q, member 2 & Kcnq2 & -2.22 & 0.001 \\
\hline 1439196_at & hook homolog 3 (Drosophila) & Hook3 & -2.22 & 0.001 \\
\hline 1420688_a_at & sarcoglycan, epsilon & Sgce & -2.24 & 0.009 \\
\hline 1435541_at & betacellulin, epidermal growth factor family member & Btc & -2.24 & 0.004 \\
\hline 1430255_at & Kruppel-like factor 5 & Klf5 & -2.24 & 0.010 \\
\hline 1425951_a_at & C-type lectin domain family 4 , member $n$ & Clec $4 n$ & -2.26 & 0.005 \\
\hline 1444502_at & PET112-like (yeast) & Pet112l & -2.26 & 0.004 \\
\hline 1434603_at & thyroid hormone receptor associated protein 2 & Thrap2 & -2.26 & 0.002 \\
\hline 1424857_a_at & tripartite motif protein 34 & Trim34 & -2.26 & 0.002 \\
\hline 1457126_at & myosin, light polypeptide 4 & Myl4 & -2.26 & 0.009 \\
\hline 1419847_at & Protein serine kinase $\mathrm{H} 1$ & AW539964 & -2.26 & 0.002 \\
\hline 1449403_at & phosphodiesterase 9A & Pde9a & -2.27 & 0.008 \\
\hline 1449135_at & SRY-box containing gene 18 & Sox18 & -2.27 & 0.000 \\
\hline 1460546_at & leucine-rich repeat LGI family, member 3 & Lgi3 & -2.27 & 0.004 \\
\hline 1418990_at & membrane-spanning 4-domains, subfamily $A$, member $4 D$ & Ms4a4d & -2.28 & 0.002 \\
\hline 1448380_at & lectin, galactoside-binding, soluble, 3 binding protein & Lgals3bp & -2.28 & 0.000 \\
\hline 1433893_s_at & sperm associated antigen 5 & Spag5 & -2.29 & 0.006 \\
\hline 1438468 at & preferentially expressed antigen in melanoma like 4 & Pramel4 /// Pramı & -2.29 & 0.003 \\
\hline
\end{tabular}


1438372_at

1453128_at

(juvenile) (human homolog)

myomesin 2

1438084 at

extra cellular link domain-containing 1

1455493_at

1440641 at

1425071_s_at

1420982_at

A disintegrin and metalloprotease domain 23

synaptic nuclear envelope 1

Vacuolar protein sorting 29 (S. pombe)

1447491_at

1441017_at

1443362_at

1437889_x_at

1457724 at

1425709_at

1422151 at

1433578_at

1418809_at

1436319_at

1433745 at

1417961_a_at

1428168_at

1443595 at

1417066_at

1435760_at

1417859_at

1425745_a_at

1442760_x_at

1452231_x_at

1428230 at

1439240_x_at

1436781 at

Leucine rich repeat containing 5

zinc finger, $\mathrm{CCHC}$ domain containing 14

Zinc finger protein 277

biglycan

cathepsin L

ring finger protein 17

opposite strand transcription unit to Stag3

hypothetical protein E130304D01

paired-lg-like receptor $A 1$

sulfatase 1

triple functional domain (PTPRF interacting)

tripartite motif protein 30

myelin protein zero-like 1

CCR4-NOT transcription complex, subunit 6-like

chaperone, $A B C 1$ activity of bc1 complex like (S. pombe)

cystatin A

growth arrest specific 7

transforming, acidic coiled-coil containing protein 2

Reticulon 4

interferon activated gene 203

protein kinase $\mathrm{C}$, nu

lin 7 homolog $b$ (C. elegans)

mannosidase 2, alpha B1

0.006

0.001

0.003

0.006

0.008

0.006

0.002

0.002

0.000

0.005

0.001

0.003

0.00

0.009

0.004

0.002

0.001

0.007

0.002

0.006

0.002

0.003

0.004

0.000

0.001

0.008

0.002

0.005

0.008

0.003

0.004

0.003

0.000

0.005

0.003 
1418623_at

1448261_at

1417982_at

1457012_at

1441344_at

1420910_at

1459769_at

1434502_x_at

1429296_at

1423555_a_at

1456080_a_at

1420534_at

1415965_at

1450202_at

1432181_s_at

1434252_at

1456494_a_at

1422423

1417885_at

1418950 at

1429806_at

1456046_at

1449872_at

1443698 at

1426433_at

1452035_at

1427676 a at

1436545_at

1443048_at

1416304_at

1426664_x_a

1455293_at

1457608_at

1453100 at

1457762_at

1422254_a_at
RAB2, member RAS oncogene family

cadherin 1

insulin induced gene 2

veloping brain homeobox 1

SPFH domain family, member 1

phosphatidic acid phosphatase type $2 \mathrm{c}$

Hypothetical gene supported by AK076800; BC048609

solute carrier family 4 (anion exchanger), member 1

RAB10, member RAS oncogene family

interferon-induced protein 44

Tumor differentially expressed 1

guanylate cyclase 1 , soluble, alpha 3

stearoyl-Coenzyme A desaturase 1

glutamate receptor, ionotropic, NMDA1 (zeta 1)

endothelial cell growth factor 1 (platelet-derived)

transmembrane and coiled coil domains 3

tripartite motif protein 30 /// tripartite motif protein 30-like

melanoma antigen, family $A, 7$

microtubule-associated protein tau

pamine receptor 2

Era (G-protein)-like 1 (E. coli)

complement component 1, q subcomponent, receptor 1

heat shock protein 3

F-box protein 39

myc target 1

procollagen, type IV, alpha 1

Glutamate receptor, ionotropic, kainate 1

deltex 4 homolog (Drosophila)

F-box only protein 21

LPS-induced TN facto

prostate cancer associated protein 6

gene model 185, (NCBI)

GTPase, IMAP family member 8

casein kinase II, alpha 2, polypeptide

Tetratricopeptide repeat domain 15

dual-specificity tyrosine-(Y)-phosphorylation regulated kinase $1 b$

\begin{tabular}{lll} 
Rab2 & -2.52 & 0.002 \\
Cdh1 & -2.53 & 0.000 \\
Insig2 & -2.53 & 0.000 \\
Dbx1 & -2.55 & 0.001 \\
Spfh1 & -2.55 & 0.004 \\
Ppap2c & -2.55 & 0.006 \\
LOC433215 & -2.55 & 0.009 \\
Slc4a1 & -2.56 & 0.005 \\
Rab10 & -2.56 & 0.007 \\
Ifi44 & -2.56 & 0.000 \\
Tde1 & -2.57 & 0.001 \\
Gucy1a3 & -2.57 & 0.003 \\
Scd1 & -2.57 & 0.000 \\
Grin1 & -2.57 & 0.004 \\
Ecgf1 & -2.59 & 0.001 \\
Tmcc3 & -2.59 & 0.000 \\
Trim30 III LOC20 & -2.59 & 0.000 \\
Magea7 & -2.60 & 0.001 \\
Mapt & -2.60 & 0.008 \\
Drd2 & -2.62 & 0.001 \\
Eral1 & -2.65 & 0.004 \\
C1qr1 & -2.66 & 0.000 \\
Hspb3 & -2.67 & 0.001 \\
Fbx039 & -2.68 & 0.002 \\
Myct1 & -2.69 & 0.000 \\
Col4a1 & -2.70 & 0.000 \\
Grik1 & -2.70 & 0.000 \\
Dtx4 & -2.71 & 0.007 \\
Fbx021 & -2.72 & 0.001 \\
Litaf & -2.73 & 0.000 \\
Pcanap6 & -2.74 & 0.000 \\
Gm185 & -2.75 & 0.010 \\
Gimap8 & -2.76 & 0.004 \\
Csnk2a2 & -2.76 & 0.003 \\
Ttc15 & -2.77 & 0.001 \\
Dyrk1b & -2.77 & 0.005 \\
& & \\
\hline
\end{tabular}


1449309_at

1454159 a a

1444171_at

1434087_at

1452783_at

1440026_at

1420426_at

1425505_at

1449007_at

1443169_at

1421769 at

1455099_at

1418746_at

1442316_x_at

1417040_a_a

1449368_at

1437801_at

1426732_at

1418449_at

1438063 at

1453571_at

1431056_a_at

1435775_at

1458617 at

1443795_at

1421548_at

1452968 at

1433691_at

1453681_at

1438404_at

1416589_at

1442086_at

1418191_at

1451597 at

1426278_at

1421678_at cytochrome P450, family 8 , subfamily b, polypeptide 1

insulin-like growth factor binding protein 2

Programmed cell death 4

5,10-methylenetetrahydrofolate reductase

fibronectin type III domain containing $3 \mathrm{~B}$

Trichorhinophalangeal syndrome I (human)

myosin VIlb

myosin, light polypeptide kinase

B-cell translocation gene 3

CCR4-NOT transcription complex, subunit 4

IM homeobox transcription factor 1 beta

monoacylglycerol O-acyltransferase 2

rain protein 17

transformation related protein 53 binding protein 1

Bcl-2-related ovarian killer protein

decorin

LIM domain containing preferred translocation partner in lipoma

desmin

ladinin

M-phase phosphoprotein 9

DEP domain containing 6

poprotein lipase

TPA regulated locus

protein kinase $\mathrm{C}$ binding protein 1

transcription factor 19

protocadherin beta 2

collagen triple helix repeat containing 1

protein phosphatase 1 , regulatory (inhibitor) subunit 3C

ATPase inhibitory factor 1

ring finger protein 144

secreted acidic cysteine rich glycoprotein

Metastasis associated 3

ubiquitin specific protease 18

transmembrane protease, serine $11 d$

interferon, alpha-inducible protein 27

inositol 1,4,5-triphosphate receptor 2

\begin{tabular}{lll} 
Cyp8b1 & -2.78 & 0.001 \\
Igfbp2 & -2.78 & 0.000 \\
Pdcd4 & -2.78 & 0.002 \\
Mthfr & -2.79 & 0.002 \\
Fndc3b & -2.79 & 0.000 \\
Trps1 & -2.79 & 0.003 \\
Myo7b & -2.80 & 0.003 \\
Mylk & -2.80 & 0.000 \\
Btg3 & -2.82 & 0.001 \\
Cnot4 & -2.83 & 0.009 \\
Lmx1b & -2.87 & 0.000 \\
Mogat2 & -2.88 & 0.009 \\
MGl:1930773 & -2.90 & 0.003 \\
Trp53bp1 & -2.91 & 0.005 \\
Bok & -2.94 & 0.000 \\
Dcn & -2.95 & 0.000 \\
Lpp & -2.97 & 0.002 \\
Des & -2.97 & 0.000 \\
Lad1 & -2.98 & 0.002 \\
Mphosph9 & -2.99 & 0.009 \\
Depdc6 & -2.99 & 0.000 \\
Lpl & -2.99 & 0.002 \\
Tparl & -3.00 & 0.000 \\
Prkcbp1 & -3.00 & 0.000 \\
Tcf19 & -3.04 & 0.001 \\
Pcdhb2 & -3.04 & 0.001 \\
Cthrc1 & -3.05 & 0.001 \\
Ppp1r3c & -3.05 & 0.000 \\
Atpif1 & -3.08 & 0.001 \\
Rnf144 & -3.10 & 0.003 \\
Sparc & -3.10 & 0.000 \\
Mta3 & -3.11 & 0.008 \\
Usp18 & -3.12 & 0.000 \\
Tmprss11d & -3.14 & 0.007 \\
Ifi27 & -3.14 & 0.001 \\
Itpr2 & -3.16 & 0.001 \\
& & \\
\hline
\end{tabular}


1436068_at

1453528_at

1437218_at

1452250 a at 1450484_a_at

1417311_at

1419703_at

1456767_at

1436058_at

1437400_at

1427829 at

1459860_x_at

1417880_at

1436778_at

1421765_at

1442927_at

1429298_at

1428372_at

1417843_s_at

1441995 at

1447394_at

1458641_at

1436181_at

1451538 at

1441704_at

1445522_at

1423447 at

1418440_at

1437609_at

1459353_at

1439479_at

1430015_at

1438294_at

1444438_at

1450264_a_at

1420722_at zinc finger and BTB domain containing 10

leukotriene $A 4$ hydrolase

fibronectin 1

procollagen, type $\mathrm{VI}$, alpha 2

thymidylate kinase family LPS-inducible member

cysteine rich protein 2

procollagen, type $\mathrm{V}$, alpha 3

leucine rich repeat and fibronectin type III domain containing 3

radical S-adenosyl methionine domain containing 2

neural precursor cell expressed, developmentally down-regulated gene 4-like

ATP-binding cassette, sub-family D (ALD), member 4

tripartite motif protein 2

glucose-6-phosphatase, catalytic

cytochrome b-245, beta polypeptide

paired box gene 5

PTK2 protein tyrosine kinase 2 beta

dimethylarginine dimethylaminohydrolase 1

suppression of tumorigenicity 5

EPS8-like 2

ural cell adhesion molecule 1

chloride channel calcium activated 6

Braf transforming gene

development and differentiation enhancing factor 2

SRY-box containing gene 9

Pleckstrin homology domain containing, family A member 5

ATPase, class I, type 8B, member 4

caseinolytic protease $X$ (E.coli)

procollagen, type VIII, alpha 1

similar to hypothetical protein

Potassium channel tetramerisation domain containing 3

lactase

peroxisomal, testis specific 1

spinocerebellar ataxia 1 homolog (human)

calcium and integrin binding family member 3

choline kinase alpha

elongation of very long chain fatty acids-like 3

\begin{tabular}{lll} 
Zbtb10 & -3.17 & 0.007 \\
Lta4h & -3.19 & 0.005 \\
Fn1 & -3.21 & 0.000 \\
Col6a2 & -3.21 & 0.003 \\
Tyki & -3.21 & 0.000 \\
Crip2 & -3.23 & 0.003 \\
Col5a3 & -3.27 & 0.001 \\
Lrfn3 & -3.34 & 0.006 \\
Rsad2 & -3.38 & 0.005 \\
Nedd4l & -3.41 & 0.001 \\
Abcd4 & -3.43 & 0.002 \\
Trim2 & -3.43 & 0.000 \\
G6pc & -3.48 & 0.000 \\
Cybb & -3.52 & 0.000 \\
Pax5 & -3.57 & 0.001 \\
Ptk2b & -3.58 & 0.000 \\
Ddah1 & -3.59 & 0.004 \\
St5 & -3.63 & 0.000 \\
Eps8l2 & -3.71 & 0.001 \\
Ncam1 & -3.75 & 0.000 \\
Clca6 & -3.77 & 0.009 \\
Braf & -3.78 & 0.004 \\
Ddef2 & -3.79 & 0.000 \\
Sox9 & -3.80 & 0.007 \\
Plekha5 & -3.85 & 0.003 \\
Atp8b4 & -4.02 & 0.000 \\
Clpx & -4.05 & 0.008 \\
Col8a1 & -4.38 & 0.008 \\
LOC381534 & -4.60 & 0.003 \\
Kctd3 & -4.64 & 0.004 \\
Lct & -4.79 & 0.000 \\
Pxt1 & -4.86 & 0.007 \\
Sca1 & -5.26 & 0.000 \\
Cib3 & -5.88 & 0.003 \\
Chka & -5.91 & 0.004 \\
Elovl3 & -6.25 & 0.001 \\
& & \\
\hline
\end{tabular}


1418918_at

1425099_a_at

1448612_at

1424857_a_at

1454902_a

1429883_at

1419483 at

1437762_at

1443340 at

1425948_a_at

1417066 at

1440360_at

1442697_at

1428230_at

1449135_at

1438121 at

1433745_at

1427551_at

1448696_at

1420688_a_a

1427357 at

1417982_at

1452907 at

1418456_a_at

1428167 a at

1455493_at

1457231_at

1418990_at

1415965 at

1447198_at

1459856_at

1460225 at

1427201_at

1444693 at

1417961_a_at

1434314_s_at insulin-like growth factor binding protein 1

aryl hydrocarbon receptor nuclear translocator-like

tripartite motif protein 34

protein kinase $\mathrm{C}$, zeta

actin-like 6A

complement component 3a receptor 1

RAB39, member RAS oncogene family

binding atopy-related autoantigen 1

solute carrier family 25 , member 30

complex like (S, pombe)

ADP-ribosylation factor-like 6 interacting protein 5

Importin 11

protein kinase $\mathrm{C}$, nu

SRY-box containing gene 18

SEC24 related gene family, member A (S. cerevisiae)

triple functional domain (PTPRF interacting)

uitin specific protease 29

hephaestin

sarcoglycan, epsilon

cytidine deaminase

insulin induced gene 2

galactosylceramidase

chemokine (C-X-C motif) ligand 14

myelin protein zero-like 1

synaptic nuclear envelope

Hypoxia inducible factor 1 , alpha subunit

membrane-spanning 4-domains, subfamily A, member 4D

stearoyl-Coenzyme A desaturase 1

RecQ protein-like

Mitochondrial ribosomal protein L13

mitochondrial ribosomal protein 63

musculoskeletal, embryonic nuclear protein

channel, voltage-dependent, beta 2 subunit

tripartite motif protein 30

RAB11 family interacting protein 5 (class I)

\begin{tabular}{lcc} 
Igfbp1 & -7.75 & 0.007 \\
Arntl & -12.98 & 0.005 \\
Sfn & -2.6 & 0.005 \\
Trim34 & -2.6 & 0.000 \\
Prkcz & -2.6 & 0.009 \\
Actl6a & -2.6 & 0.009 \\
C3ar1 & -2.6 & 0.002 \\
Rab39 & -2.6 & 0.003 \\
Cbara1 & -2.6 & 0.003 \\
Slc25a30 & -2.7 & 0.002 \\
Cabc1 & -2.7 & 0.001 \\
Arl6ip5 & -2.7 & 0.004 \\
Ipo11 & -2.7 & 0.003 \\
Prkcn & -2.7 & 0.000 \\
Sox18 & -2.7 & 0.000 \\
Sec24a & -2.7 & 0.008 \\
Trio & -2.7 & 0.000 \\
Usp29 & -2.7 & 0.007 \\
Heph & -2.7 & 0.001 \\
Sgce & -2.7 & 0.000 \\
Cda & -2.7 & 0.008 \\
Insig2 & -2.7 & 0.000 \\
Galc & -2.7 & 0.000 \\
Cxcl14 & -2.7 & 0.008 \\
Mpzl1 & -2.7 & 0.006 \\
Syne1 & -2.7 & 0.000 \\
Hif1a & -2.7 & 0.001 \\
Ms4a4d & -2.7 & 0.005 \\
Scd1 & -2.7 & 0.001 \\
Recql & -2.8 & 0.008 \\
Mrpl13 & -2.8 & 0.003 \\
Mrp63 & -2.8 & 0.002 \\
Mustn1 & -2.8 & 0.002 \\
Cacnb2 & -2.8 & 0.003 \\
Trim30 & -2.8 & 0.000 \\
Rab11fip5 & -2.8 & 0.003 \\
& & \\
\hline
\end{tabular}


1432181_s_at 1425745_a_at 1433053_at

1418293 at

1448261_at

1443421_s_at

1418603 a

1456080_a_at

1419044 at

1449105_at

1421028_a_at

1448834_at

1439660 at

1444127_at

1453128_at

1420982 at

1435541_at

1433147_at

1452764_at

1446674_at

1428396_at

1454159_a_at

1453077_a_at

1426318_at

1429653 at

1427993_at

1416023_at

1438939_x_at

1453224 at

1446329_at

1419406_a_at

1457688 at

1420615_at

1443362_at

1441536_at

1417153_at endothelial cell growth factor 1 (platelet-derived)

transforming, acidic coiled-coil containing protein 2

integrin beta 2-like

interferon-induced protein with tetratricopeptide repeats 2

cadherin 1

protocadherin beta 15

arginine vasopressin receptor $1 \mathrm{~A}$

Tumor differentially expressed 1

contactin associated protein 4

$\mathrm{SH} 2$ domain protein $2 \mathrm{~A}$

myocyte enhancer factor 2C

forkhead box M1

human immunodeficiency virus type I enhancer binding protein 3

Ankyrin repeat and SOCS box-containing protein 1

extra cellular link domain-containing 1

RNA-binding region (RNP1, RRM) containing 2

betacellulin, epidermal growth factor family member

caldesmon 1

suppressor of cytokine signaling 6

Mitogen activated protein kinase kinase 5

SMAD specific E3 ubiquitin protein ligase 1

insulin-like growth factor binding protein 2

small nuclear RNA activating complex, polypeptide 3

serine (or cysteine) proteinase inhibitor, clade $B$, member $1 \mathrm{~b}$

genetic suppressor element 1

RUN and FYVE domain-containing 2

fatty acid binding protein 3 , muscle and heart

Necdin

zinc finger, A20 domain containing 2

$\mathrm{G}$ kinase anchoring protein 1

B-cell CLL/lymphoma 11A (zinc finger protein)

zinc finger protein 398

ash2 (absent, small, or homeotic)-like (Drosophila)

c finger protein 277

3-hydroxy-3-methylglutaryl-Coenzyme A synthase 1

BTB (POZ) domain containing 14A

$\begin{array}{lll}\text { Ecgf1 } & -2.8 & 0.000 \\ \text { Tacc2 } & -2.8 & 0.007 \\ \text { Itgb2l } & -2.8 & 0.002 \\ \text { Ifit2 } & -2.8 & 0.009 \\ \text { Cdh1 } & -2.8 & 0.000 \\ \text { Pcdhb15 } & -2.8 & 0.009 \\ \text { Avpr1a } & -2.8 & 0.007 \\ \text { Tde1 } & -2.8 & 0.000 \\ \text { Cntnap4 } & -2.8 & 0.003 \\ \text { Sh2d2a } & -2.8 & 0.000 \\ \text { Mef2c } & -2.8 & 0.003 \\ \text { Foxm1 } & -2.8 & 0.009 \\ \text { Hivep3 } & -2.9 & 0.004 \\ \text { Asb1 } & -2.9 & 0.007 \\ \text { Xlkd1 } & -2.9 & 0.005 \\ \text { Rnpc2 } & -2.9 & 0.002 \\ \text { Btc } & -2.9 & 0.004 \\ \text { Cald1 } & -2.9 & 0.006 \\ \text { Socs6 } & -2.9 & 0.009 \\ \text { Map2k5 } & -2.9 & 0.000 \\ \text { Smurf1 } & -2.9 & 0.005 \\ \text { Igfbp2 } & -2.9 & 0.000 \\ \text { Snapc3 } & -2.9 & 0.000 \\ \text { Serpinb1b } & -2.9 & 0.006 \\ \text { Gse1 } & -2.9 & 0.000 \\ \text { Rufy2 } & -2.9 & 0.010 \\ \text { Fabp3 } & -2.9 & 0.001 \\ \text { Ndn } & -2.9 & 0.004 \\ \text { Za20d2 } & -2.9 & 0.007 \\ \text { Gkap1 } & -2.9 & 0.003 \\ \text { Bcl11a } & -2.9 & 0.002 \\ \text { Zfp398 } & -2.9 & 0.002 \\ \text { Ash2l } & -3.0 & 0.002 \\ \text { Zfp277 } & -3.0 & 0.000 \\ \text { Hmgcs1 } & -3.0 & 0.006 \\ \text { Btbd14a } & -3.0 & 0.003\end{array}$




$\begin{array}{ll}\text { 1459942_at } & \text { Open reading frame 34 } \\ \text { 1436500_at } & \text { Ribosomal protein S24 } \\ \text { 1420561_at } & \text { transient receptor potential cation channel, subfamily C, member } 7 \\ \text { 1445918_at } & \text { Transmembrane protein } 2 \\ \text { 1449309_at } & \text { cytochrome P450, family 8, subfamily b, polypeptide 1 } \\ \text { 1438084_at } & \text { A disintegrin and metalloprotease domain 23 } \\ \text { 1446311_at } & \text { membrane bound C2 domain containing protein } \\ \text { 1425631_at } & \text { protein phosphatase 1, regulatory (inhibitor) subunit 3C } \\ \text { 1421609_a_at } & \text { camello-like 3 } \\ \text { 1435061_at } & \text { nudix (nucleoside diphosphate linked moiety X)-type motif 11 } \\ \text { 1425951_a_at } & \text { C-type lectin domain family 4, member n } \\ \text { 1442381_at } & \text { Muskelin 1, intracellular mediator containing kelch motifs } \\ \text { 1440641_at } & \text { Vacuolar protein sorting 29 (S. pombe) } \\ \text { 1445105_at } & \text { P300/CBP-associated factor } \\ \text { 1434252_at } & \text { transmembrane and coiled coil domains 3 } \\ \text { 1418803_a_at } & \text { Fas ligand (TNF superfamily, member 6) } \\ \text { 1444502_at } & \text { PET112-like (yeast) } \\ \text { 1456494_a_at } & \text { tripartite motif protein 30 /II tripartite motif protein 30-like } \\ & \\ \text { 1442035_at } & \text { cholinergic receptor, nicotinic, alpha polypeptide 5 } \\ \text { 1418623_at } & \text { RAB2, member RAS oncogene family } \\ \text { 1446107_at } & \text { Serine/threonine kinase 24 (STE20 homolog, yeast) } \\ \text { 1422327_s_at } & \text { glucose-6-phosphate dehydrogenase 2 } \\ & \\ \text { 1426997_at } & \text { thyroid hormone receptor alpha } \\ \text { 1428051_a_at } & \text { calcium channel, voltage-dependent, L type, alpha 1D subunit } \\ \text { 1443349_at } & \text { Dedicator of cytokinesis 10 } \\ \text { 1459154_at } & \text { Eyes absent 3 homolog (Drosophila) } \\ \text { 1418746_at } & \text { brain protein 17 } \\ \text { 1449368_at } & \text { decorin } \\ \text { 1442192_at } & \text { thymidylate synthase } \\ \text { 1456046_at } & \text { complement component 1, q subcomponent, receptor 1 } \\ \text { 1423555_a_at } & \text { interferon-induced protein 44 } \\ \text { 1458715_at } & \text { Caspase 6 } \\ \text { 1453755_at } & \text { U7 snRNP-specific Sm-like protein LSM11 } \\ \text { 1451063_at } & \text { syntaxin binding protein } 4 \\ & \end{array}$

\begin{tabular}{lll} 
ORF34 & -3.0 & 0.004 \\
Rps24 & -3.0 & 0.002 \\
Trpc7 & -3.0 & 0.006 \\
Tmem2 & -3.0 & 0.000 \\
Cyp8b1 & -3.0 & 0.001 \\
Adam23 & -3.0 & 0.000 \\
Mbc2 & -3.0 & 0.003 \\
Ppp1r3c & -3.0 & 0.000 \\
Cml3 & -3.1 & 0.010 \\
Nudt11 & -3.1 & 0.008 \\
Clec4n & -3.1 & 0.002 \\
Mkln1 & -3.1 & 0.001 \\
Vps29 & -3.1 & 0.001 \\
Pcaf & -3.1 & 0.001 \\
Tmcc3 & -3.1 & 0.000 \\
Fasl & -3.1 & 0.009 \\
Pet112I & -3.1 & 0.007 \\
Trim30 III & -3.1 & 0.000 \\
LOC209387 & & \\
Chrna5 & -3.1 & 0.006 \\
Rab2 & -3.1 & 0.001 \\
Stk24 & -3.1 & 0.002 \\
G6pd2 III G6pdx & -3.1 & 0.006 \\
Thra & & \\
Cacna1d & -3.1 & 0.005 \\
Dock10 & -3.1 & 0.008 \\
Eya3 & -3.2 & 0.003 \\
MGI:1930773 & -3.2 & 0.001 \\
Dcn & -3.2 & 0.000 \\
Tyms & -3.2 & 0.000 \\
C1qr1 & -3.2 & 0.005 \\
Ifi44 & -3.2 & 0.000 \\
Casp6 & -3.2 & 0.000 \\
Lsm11 & -3.2 & 0.000 \\
Stxbp4 & -3.2 & 0.001 \\
& -3.2 & 0.004 \\
\hline
\end{tabular}


1440647_at

1453571_at

1429806_at

1457126 at

1455293_at

1426664_x_at

1443698 at

1450156_a_at

1447445 at

1446167_at

1425505_at

1456354_at

1448551_a_at

1427095_at

1426140_x_at

1418809

1442760_x_at

1434087_at

1438468_at

1443540_at

1441017_at

1420729 at

1430255_at

1449007_at

1457369 at

1429402_at

1460546_at

1417859_at

1437801_at

1440141_at

1441852_x_a

1451889_at

1416589_at

1457762 at

1417896_at signal-induced proliferation-associated 1 like 1

DEP domain containing 6

Era (G-protein)-like 1 (E. coli)

myosin, light polypeptide 4

gene model 185, (NCBI)

prostate cancer associated protein 6

F-box protein 39

hyaluronan mediated motility receptor (RHAMM)

Sidekick homolog 2 (chicken)

Homeodomain interacting protein kinase 2

myosin, light polypeptide kinase

cholinergic receptor, nicotinic, alpha polypeptide 4

tripartite motif protein 2

CUB domain containing protein 1

killer cell lectin-like receptor, subfamily A, member 19

paired-lg-like receptor $\mathrm{A} 1$

Reticulon 4

5,10-methylenetetrahydrofolate reductase

preferentially expressed antigen in melanoma like 4

mitogen activated protein kinase kinase kinase 1

zinc finger, $\mathrm{CCHC}$ domain containing 14

2-cell-stage, variable group, member 1

Kruppel-like factor 5

B-cell translocation gene 3

Phosphatase and actin regulator 4

glycosyltransferase 8 domain containing 2

leucine-rich repeat LGI family, member 3

growth arrest specific 7

LIM domain containing preferred translocation partner in lipoma

potassium voltage-gated channel, subfamily Q, member 2

APG16 autophagy 16-like (S. cerevisiae)

Notch gene homolog 2 (Drosophila)

secreted acidic cysteine rich glycoprotein

tratricopeptide repeat domain 15

tight junction protein 3

$\begin{array}{lll}\text { Sipa1l1 } & -3.2 & 0.007 \\ \text { Depdc6 } & -3.2 & 0.000 \\ \text { Eral1 } & -3.2 & 0.000 \\ \text { Myl4 } & -3.2 & 0.001 \\ \text { Gm185 } & -3.2 & 0.001 \\ \text { Pcanap6 } & -3.2 & 0.000 \\ \text { Fbxo39 } & -3.2 & 0.004 \\ \text { Hmmr } & -3.2 & 0.001 \\ \text { Sdk2 } & -3.2 & 0.010 \\ \text { Hipk2 } & -3.2 & 0.000 \\ \text { Mylk } & -3.2 & 0.000 \\ \text { Chrna4 } & -3.2 & 0.004 \\ \text { Trim2 } & -3.3 & 0.004 \\ \text { Cdcp1 } & -3.3 & 0.001 \\ \text { Klra19 } & -3.3 & 0.006 \\ \text { Pira1 } & -3.3 & 0.002 \\ \text { Rtn4 } & -3.3 & 0.001 \\ \text { Mthfr } & -3.3 & 0.000 \\ \text { Pramel4 III } & -3.3 & 0.000 \\ \text { Pramel5 } & & \\ \text { Map3k1 } & -3.3 & 0.001 \\ \text { Zcchc14 } & -3.3 & 0.000 \\ \text { MGI:1933437 } & -3.3 & 0.005 \\ \text { Klf5 } & -3.3 & 0.000 \\ \text { Btg3 } & -3.3 & 0.002 \\ \text { Phactr4 } & -3.3 & 0.001 \\ \text { Glt8d2 } & -3.3 & 0.007 \\ \text { Lgi3 } & -3.4 & 0.004 \\ \text { Gas7 } & -3.4 & 0.000 \\ \text { Lpp } & -3.4 & 0.002 \\ \text { Kcnq2 } & -3.4 & 0.005 \\ \text { Apg16l } & -3.4 & 0.007 \\ \text { Notch2 } & -3.4 & 0.007 \\ \text { Sparc } & -3.4 & 0.000 \\ \text { Ttc15 } & -3.5 & 0.003 \\ \text { Tjp3 } & -3.5 & 0.007\end{array}$


1435760_at

1417040_a_at

1441344_at

1439240_x_at

1417311_at

1458381_at

1419847 at

1418449_at

1422423_at

1443048_at

1419339_at

1422254_a_at

1431319 at

1425709_at

1448228_at

1457012 at

1418950_at

1457608_at

1452017_at

1437218_at

1438404_at

1433133_at

1418191 at

1431263_at

1427702 at

1431056_a_a

1417880_at

1421561_at

1420534_at

1426278_at

1426294_at

1436319 at

1419703_at

1420426_at

1456767_at

1453041_at cystatin A

-2-related ovarian killer protein

SPFH domain family, member 1

7 homolog $b$ (C. elegans)

cysteine rich protein 2

chloride intracellular channel 5

Protein serine kinase $\mathrm{H} 1$

ladinin

elanoma antigen, family $\mathrm{A}, 7$

F-box only protein 21

neuraminidase 3

dual-specificity tyrosine-(Y)-phosphorylation regulated kinase $1 b$

unc-51-like kinase 4 (C. elegans)

ring finger protein 17

lysyl oxidase

developing brain homeobox 1

dopamine receptor 2

GTPase, IMAP family member 8

SRY-box containing gene 15

fibronectin 1

ring finger protein 144

EDAR (ectodysplasin-A receptor)-associated death domain

ubiquitin specific protease 18

protein kinase, AMP-activated, gamma 2 non-catalytic subunit

zinc finger protein 1

lipoprotein lipase

glucose-6-phosphatase, catalytic

basic helix-loop-helix domain containing, class B4

guanylate cyclase 1 , soluble, alpha 3

interferon, alpha-inducible protein 27

hyaluronan and proteoglycan link protein 1

sulfatase 1

procollagen, type $\mathrm{V}$, alpha 3

myosin VIlb

leucine rich repeat and fibronectin type III domain containing 3

Trp53 inducible protein 5

$\begin{array}{lll}\text { MGI:3524930 } & -3.5 & 0.000 \\ \text { Bok } & -3.5 & 0.000 \\ \text { Spfh1 } & -3.5 & 0.001 \\ \text { Lin7b } & -3.5 & 0.009 \\ \text { Crip2 } & -3.5 & 0.001 \\ \text { Clic5 } & -3.5 & 0.001 \\ \text { AW539964 } & -3.5 & 0.001 \\ \text { Lad1 } & -3.5 & 0.002 \\ \text { Magea7 } & -3.5 & 0.002 \\ \text { Fbxo21 } & -3.5 & 0.000 \\ \text { Neu3 } & -3.5 & 0.003 \\ \text { Dyrk1b } & -3.6 & 0.010 \\ \text { Ulk4 } & -3.6 & 0.009 \\ \text { Rnf17 } & -3.6 & 0.004 \\ \text { Lox } & -3.6 & 0.001 \\ \text { Dbx1 } & -3.6 & 0.001 \\ \text { Drd2 } & -3.6 & 0.000 \\ \text { Gimap8 } & -3.6 & 0.000 \\ \text { Sox15 } & -3.6 & 0.004 \\ \text { Fn1 } & -3.6 & 0.000 \\ \text { Rnf144 } & -3.7 & 0.000 \\ \text { Edaradd } & -3.7 & 0.009 \\ \text { Usp18 } & -3.7 & 0.000 \\ \text { Prkag2 } & -3.7 & 0.004 \\ \text { Zfp1 } & -3.7 & 0.004 \\ \text { Lpl } & -3.7 & 0.005 \\ \text { G6pc } & -3.7 & 0.000 \\ \text { Bhlhb4 } & -3.8 & 0.005 \\ \text { Gucy1a3 } & -3.8 & 0.002 \\ \text { Ifi27 } & -3.8 & 0.002 \\ \text { Hapln1 } & -3.8 & 0.005 \\ \text { Sulf1 } & -3.8 & 0.007 \\ \text { Col5a3 } & -3.9 & 0.002 \\ \text { Myo7b } & -3.9 & 0.008 \\ \text { Lrfn3 } & -3.9 & 0.000 \\ \text { Trp53i5 } & -3.9 & 0.005 \\ \text { H. } & & \end{array}$

.000

0.009

.001

002

0.010

0.001

000

0.004

0.009

0.005

.002

.002

0.002

0.000

0.005 


$\begin{array}{ll}\text { 1450202_at } & \text { glutamate receptor, ionotropic, NMDA1 (zeta 1) } \\ \text { 1419726_at } & \text { a disintegrin and metalloprotease domain 18 } \\ \text { 1429298_at } & \text { dimethylarginine dimethylaminohydrolase 1 } \\ \text { 1422978_at } & \text { cytochrome b-245, beta polypeptide } \\ \text { 1434502_x_at } & \text { solute carrier family 4 (anion exchanger), member } 1 \\ \text { 1455099_at } & \text { monoacylglycerol O-acyltransferase 2 } \\ \text { 1427676_a_at } & \text { Glutamate receptor, ionotropic, kainate 1 } \\ \text { 1459026_at } & \text { SKI interacting protein } \\ \text { 1449514_at } & \text { G protein-coupled receptor kinase 5 } \\ \text { 1443630_at } & \text { Protein phosphatase 3, catalytic subunit, alpha isoform } \\ \text { 1444171_at } & \text { Programmed cell death 4 } \\ \text { 1428372_at } & \text { suppression of tumorigenicity 5 } \\ \text { 1436068_at } & \text { zinc finger and BTB domain containing 10 } \\ \text { 1452250_a_at } & \text { procollagen, type VI, alpha 2 } \\ \text { 1421769_at } & \text { LIM homeobox transcription factor 1 beta } \\ \text { 1417843_s_at } & \text { EPS8-like 2 } \\ \text { 1451375_at } & \text { ets homologous factor } \\ \text { 1426433_at } & \text { myc target 1 } \\ \text { 1457551_at } & \text { Activin A receptor, type 1 } \\ \text { 1453681_at } & \text { ATPase inhibitory factor 1 } \\ \text { 1435756_at } & \text { sterile alpha motif domain containing 10 } \\ \text { 1449872_at } & \text { heat shock protein } 3 \\ \text { 1424950_at } & \text { SRY-box containing gene 9 } \\ \text { 1423447_at } & \text { caseinolytic protease X (E.coli) } \\ \text { 1436181_at } & \text { development and differentiation enhancing factor } 2 \\ \text { 1453528_at } & \text { leukotriene A4 hydrolase } \\ \text { 1436593_at } & \text { Unknown (protein for MGC:58818) } \\ \text { 1451597_at } & \text { transmembrane protease, serine 11d } \\ \text { 1437932_a_at } & \text { claudin 1 } \\ \text { 1426732_at } & \text { desmin } \\ \text { 1444294_at } & \text { 5-oxoprolinase (ATP-hydrolysing) } \\ \text { 1443795_at } & \text { transcription factor 19 } \\ \text { 1424811_at } & \text { camello-like 5 } \\ \text { 1421678_at } & \text { inositol 1,4,5-triphosphate receptor 2 } \\ \text { 1421548_at } & \text { protocadherin beta 2 } \\ \text { 1417860_a_at } & \text { spondin 2, extracellular matrix protein } \\ & \end{array}$

\begin{tabular}{lll} 
Grin1 & -3.9 & 0.001 \\
Adam18 & -3.9 & 0.003 \\
Ddah1 & -3.9 & 0.003 \\
Cybb & -3.9 & 0.002 \\
Slc4a1 & -4.0 & 0.001 \\
Mogat2 & -4.0 & 0.001 \\
Grik1 & -4.0 & 0.000 \\
Skiip & -4.0 & 0.000 \\
Gprk5 & -4.1 & 0.009 \\
Ppp3ca & -4.1 & 0.008 \\
Pdcd4 & -4.1 & 0.001 \\
St5 & -4.1 & 0.000 \\
Zbtb10 & -4.1 & 0.006 \\
Col6a2 & -4.1 & 0.001 \\
Lmx1b & -4.2 & 0.000 \\
Eps8I2 & -4.2 & 0.004 \\
Ehf & -4.2 & 0.002 \\
Myct1 & -4.3 & 0.000 \\
Acvr1 & -4.3 & 0.006 \\
Atpif1 & -4.3 & 0.000 \\
Samd10 & -4.4 & 0.004 \\
Hspb3 & -4.4 & 0.006 \\
Sox9 & -4.4 & 0.007 \\
Clpx & -4.4 & 0.006 \\
Ddef2 & -4.5 & 0.000 \\
Lta4h & -4.5 & 0.009 \\
RP23-96I9.2 & -4.6 & 0.008 \\
Tmprss11d & -4.6 & 0.002 \\
Cldn1 & -4.6 & 0.005 \\
Des & -4.6 & 0.002 \\
Oplah & -4.6 & 0.008 \\
Tcf19 & -4.6 & 0.001 \\
Cm15 & -4.7 & 0.007 \\
Itpr2 & -4.7 & 0.003 \\
Pcdhb2 & -4.8 & 0.000 \\
Spon2 & -5.0 & 0.001 \\
\hline
\end{tabular}


1425544_at

1452968_at

1442927_at

1451906 at

1447394_at

1427829_at

1441995_at

1445111_at

1421765 at

1438294_at

1450264_a_at

1420722_at

1445522 at

1436207_at

1444438_at

1459353 at

1439479_at

1430015_at

1418918_at pleckstrin homology domain containing, family A member 5

collagen triple helix repeat containing 1

PTK2 protein tyrosine kinase 2 beta

UBX domain containing 3

chloride channel calcium activated 6

ATP-binding cassette, sub-family D (ALD), member 4

Neural cell adhesion molecule 1

SEC8-like 1 (S. cerevisiae)

paired box gene 5

spinocerebellar ataxia 1 homolog (human)

choline kinase alpha

elongation of very long chain fatty acids-like 3

ATPase, class I, type 8B, member 4

Transcription factor 3

calcium and integrin binding family member 3

Potassium channel tetramerisation domain containing 3

\section{lactase}

oxisomal, testis specific 1

insulin-like growth factor binding protein 1

$\begin{array}{lll}\text { Plekha5 } & -5.0 & 0.006 \\ \text { Cthrc1 } & -5.2 & 0.009 \\ \text { Ptk2b } & -5.2 & 0.000 \\ \text { Ubxd3 } & -5.3 & 0.001 \\ \text { Clca6 } & -5.5 & 0.007 \\ \text { Abcd4 } & -5.7 & 0.005 \\ \text { Ncam1 } & -5.7 & 0.000 \\ \text { Sec8l1 } & -5.8 & 0.001 \\ \text { Pax5 } & -6.0 & 0.000 \\ \text { Sca1 } & -6.2 & 0.000 \\ \text { Chka } & -6.7 & 0.001 \\ \text { Elovl3 } & -6.8 & 0.001 \\ \text { Atp8b4 } & -6.9 & 0.001 \\ \text { Tcf3 } & -7.0 & 0.003 \\ \text { Cib3 } & -7.4 & 0.001 \\ \text { Kctd3 } & -7.4 & 0.006 \\ \text { Lct } & -7.8 & 0.000 \\ \text { Pxt1 } & -7.9 & 0.001 \\ \text { Igfbp1 } & -8.6 & 0.005\end{array}$

